Aus dem Department für Veterinärwissenschaften der Tierärztlichen Fakultät der Ludwig-Maximilians-Universität München Arbeit angefertigt unter der Leitung von Priv. Doz. Dr. Johann Maierl

Angefertigt am Department of Small Animal Clinical Sciences College of Veterinary Medicine and Biomedical Sciences Texas A\&M University, College Station, TX, USA (Dr. Sharon Kerwin)

\title{
Accuracy of Conventional Radiography and Computed Tomography in Predicting Implant Position in Relation to the Vertebral Canal in Dogs
}

Thesis for the attainment of the title Doctor in Veterinary Medicine from the Faculty of Veterinary Medicine of the Ludwig-Maximilians University Munich

By

Bianca Felicitas Hettlich

Krefeld

Munich 2011 
Gedruckt mit der Genehmigung der Tierärztlichen Fakultät der LudwigMaximilians-Universität München

$\begin{array}{ll}\text { Dekan: } & \text { Univ.-Prof. Dr. Braun } \\ \text { Berichterstatter: } & \text { Priv.-Doz. Dr. Maierl } \\ \text { Korreferentin: } & \text { Univ.-Prof. Dr. Matis }\end{array}$

Tag der Promotion: 12. Februar 2011 
Dedicated with all my heart to my father

Dr. Frank Hettlich

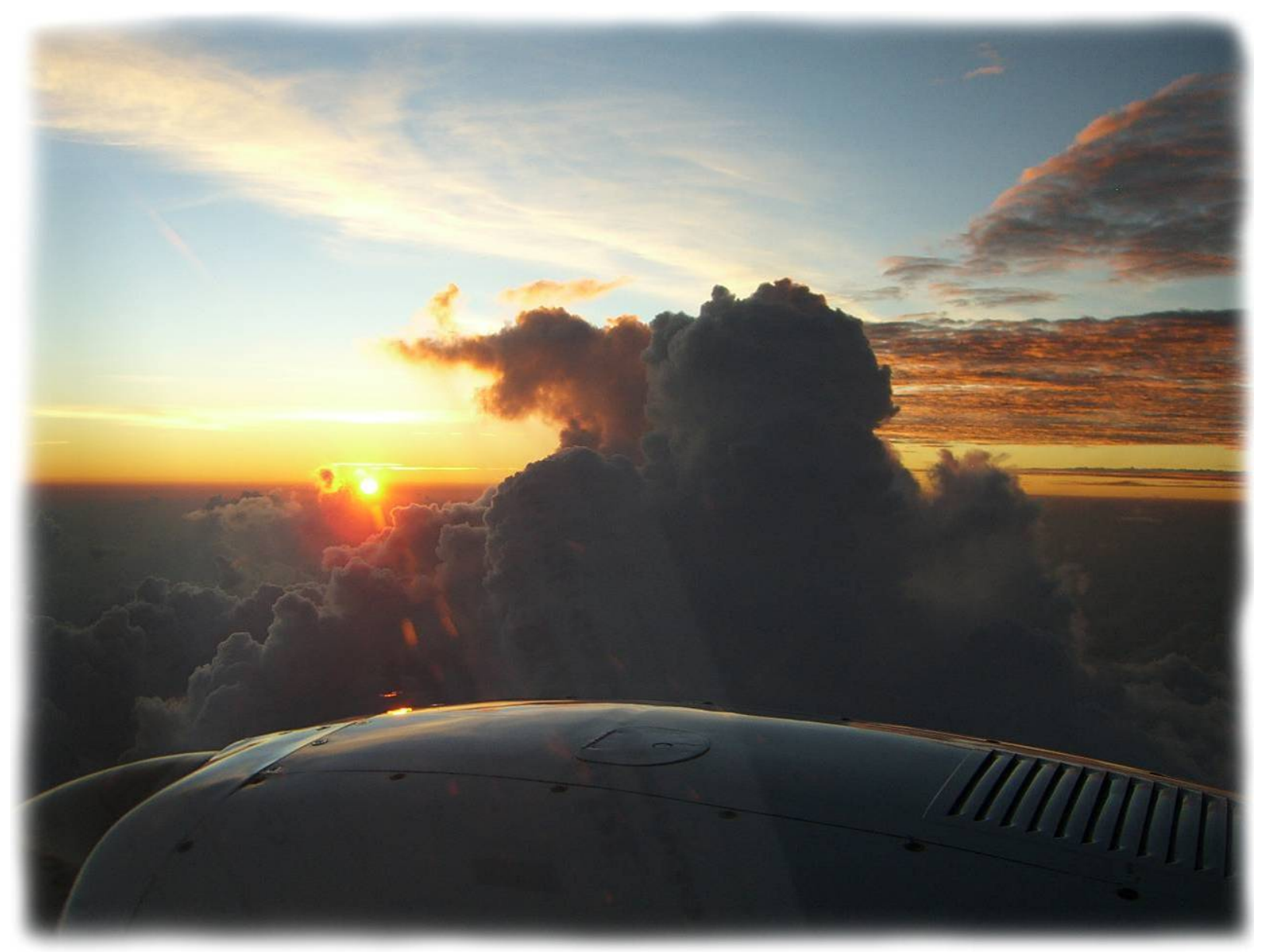


1 Introduction

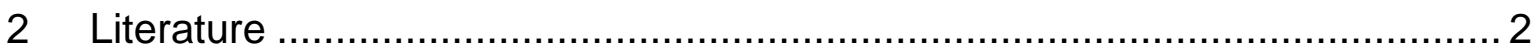

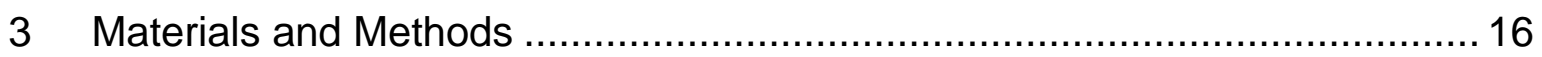

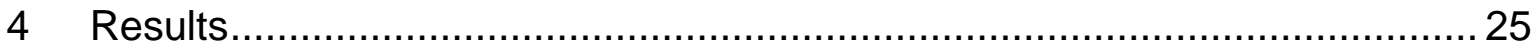

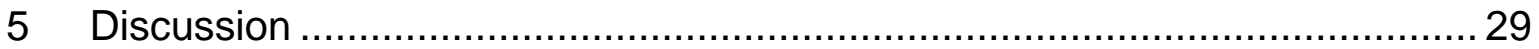

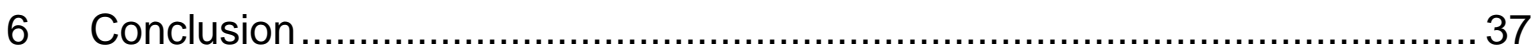

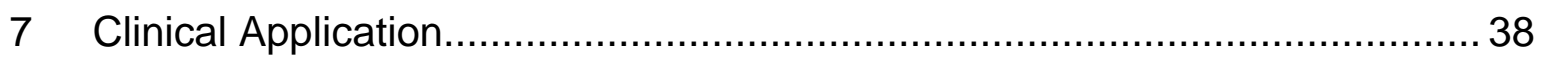

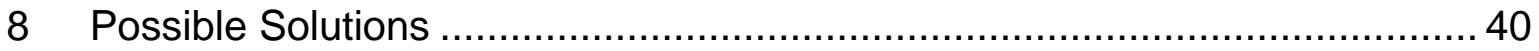

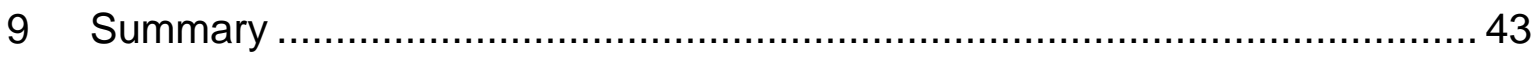

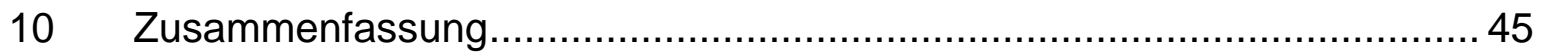

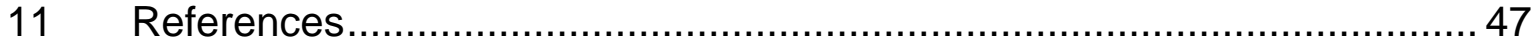

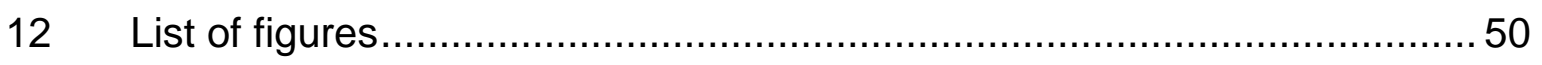

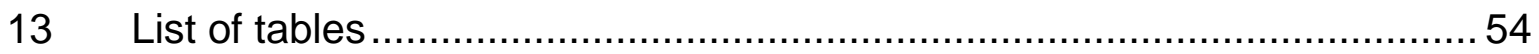




\section{Abbreviations}

$\begin{array}{ll}\text { AA } & \text { Atlanto-axial } \\ \mathrm{C} & \text { Cervical vertebra } \\ \text { Co } & \text { Degrees Celsius } \\ \mathrm{Cd} & \text { Caudal } \\ \mathrm{Cl} & \text { Confidence interval } \\ \mathrm{CT} & \text { Computed tomography } \\ \mathrm{DV} & \text { Dorsoventral } \\ \mathrm{kg} & \text { Kilogram } \\ \mathrm{L} & \text { Lumbar vertebra } \\ \mathrm{n} & \text { Number } \\ \text { PMMA } & \text { Polymethylmethacrylate } \\ \mathrm{S} & \text { Sacral vertebra } \\ \text { SOP } & \text { String of Pearls } \\ \text { TL } & \text { Thoracolumbar } \\ \text { T } & \text { Thoracic vertebra } \\ \text { VD } & \text { Ventrodorsal }\end{array}$


This dissertation is based on the study published in the Journal of Veterinary Surgery:

Hettlich BF, Fosgate GT, Kerwin SC, Levine JM, Young B, Walker M, Griffin J, Maierl J. Accuracy of conventional radiography versus computed tomography in predicting implant position in relation to the vertebral canal in dogs. Vet Surg, 2010 Aug; 39(6): 680-687.

Text marked in italics indicates the extended parts in "literature" and "discussion" as requested by the Promotionsordnung (14. Juli 2003, geändert 15. Januar 2007). 


\section{Introduction}

Spinal fixation is used for treatment of canine vertebral column disorders such as fractures or luxations, caudal cervical spondylomyelopathy, atlantoaxial instability, lumbosacral instability, ${ }^{1}$ congenital deformities, ${ }^{2}$ and pathologic instability because of diskospondylitis ${ }^{3}$ or neoplasia ${ }^{4}$. Either internal or external spinal fixation techniques can be used depending on the affected vertebrae. Stabilization techniques with insertion of implants into the pedicle and vertebral bodies include the use of pins and polymethylmethacrylate (PMMA), screws and PMMA, vertebral body plates, string of pearls plates, clamp rod internal fixator, and external skeletal spinal fixation. ${ }^{5-13}$ Recommendations for landmarks and ideal implant insertion angles in different anatomic locations along the canine vertebral column have been reported. ${ }^{12-18}$ While these recommendations are valuable and important, they do not eliminate the potential for incorrect implant placement. Inherent complications associated with these procedures include implant penetration into the vertebral canal with the possibility of iatrogenic injury to local neural and vascular structures. Detecting vertebral canal violation by an implant may be critical to surgical success and patient recovery.

We are unaware of studies evaluating the accuracy of conventional radiography and CT for assessment spinal implant position relative to the vertebral canal. Thus our purpose was to compare the ability of conventional radiography and CT to accurately assess implant penetration into the vertebral canal. Our hypothesis was that CT would be significantly more accurate than radiography in evaluating vertebral canal violation. 


\section{Literature}

Vertebral Anatomy

The canine vertebral column consists of approximately 50 individual bones with a distribution of vertebrae into five groups - cervical $(C, n=7)$, thoracic ( $T$, $n=13)$, lumbar ( $L, n=7)$, sacral $(S, n=3)$ and caudal or coccygeal (Cd, $n= \pm 20)$. Caudal vertebral numbers can vary and are often less than 20. The number of vertebrae in the other groups is usually constant; however, if numbers vary, it mostly involves the thoracolumbar or lumbosacral spine and it is often due to the development of transitional vertebrae. It is rare to have a change in number of cervical vertebrae. All vertebrae remain separate and articulate with one-another except the three sacral vertebrae, which fuse and form a single bone, the os sacrum. Most vertebrae consist of a vertebral arch that rests on the vertebral body. The arch consists of a left and right pedicle, which support the lamina dorsally. Paired cranial and caudal articular processes form articulations between adjacent vertebrae. The unpaired spinous process and the paired transverse, accessory and mammillary processes provide areas for muscular attachment. The vertebral body and arch together form the vertebral foramen; the sum of all vertebral foramina forms the vertebral canal. The vertebral canal houses and protects the spinal cord and nerve roots. Notches in the cranial and caudal aspect of adjacent pedicles form the intervertebral foramen through which the spinal nerves, arteries and veins exit/enter the vertebral canal. Transverse processes of the cervical vertebrae C2-C6 have a transverse foramen, which is often absent in C7. This foramen houses the vertebral artery and vein as well as the vertebral nerve bilaterally. Anatomical similarities and differences between vertebrae of different groups are depicted in Figure 1, Figure 2 and Figure 3. 

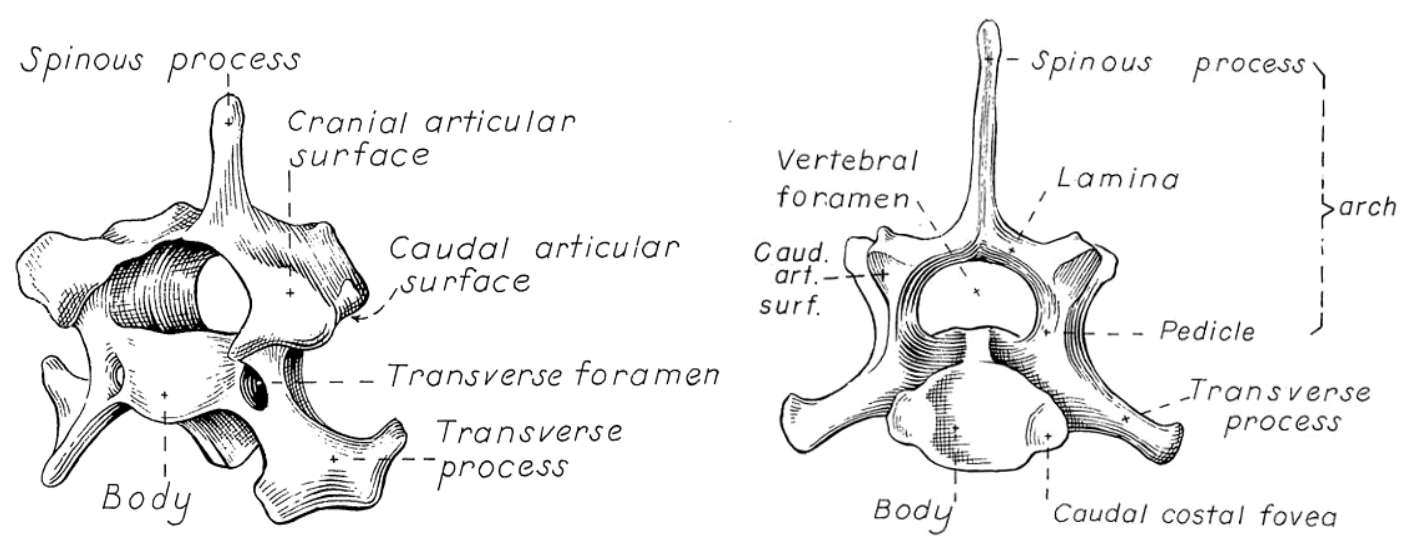

Figure 1: Craniolateral view of the $5^{\text {th }}$ (left) and caudal view of the $7^{\text {th }}$ cervical vertebra. From: Miller's Anatomy of the dog, $3^{\text {rd }}$ edition, WB Saunders 1993.
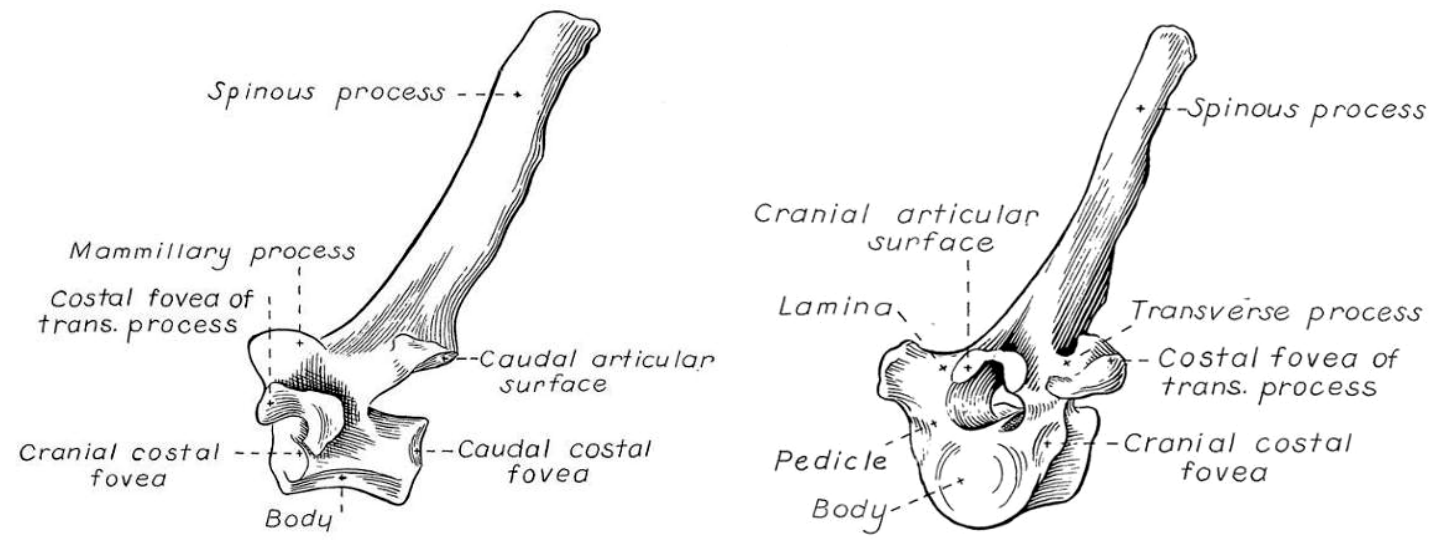

Figure 2: Lateral view of the $1^{\text {st }}$ (left) and craniolateral view of the $6^{\text {th }}$ thoracic vertebra. From: Miller's Anatomy of the dog, $3^{\text {rd }}$ edition, WB Saunders 1993.
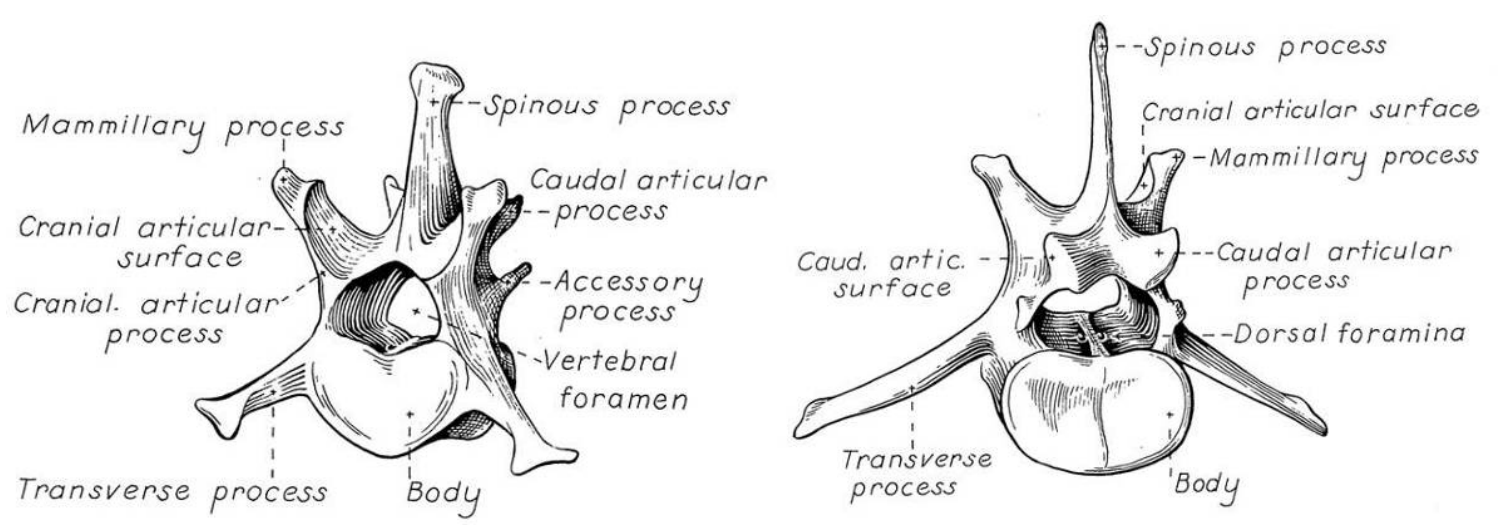

Figure 3: Craniolateral view of the $1^{\text {st }}$ (left) and caudolateral view of the $5^{\text {th }}$ lumbar vertebra. From: Miller's Anatomy of the dog, $3^{\text {rd }}$ edition, WB Saunders 1993. 
The intervertebral disk is an important stabilizer of the spine and attaches the vertebral endplate of one vertebral body to the adjacent one. The disk is composed of the gelatinous nucleus pulposus and the tough outer ring, the anulus fibrosus. The disk forms part of the ventral aspect of the vertebral canal and also the ventral border the intervertebral foramen. Other stabilizers are the articular processes with their associated synovial membranes and spinal ligaments. Important ligaments in proximity to the spinal cord are the dorsal and ventral longitudinal ligament, the interarcuate ligament (ligamentum flavum) and the intercapital ligament (Figure 4). The dorsal longitudinal ligament runs along the dorsal aspect of the vertebral bodies on the floor of the vertebral canal. It extends from the dens of the axis (C2) to the end of the vertebral canal in the caudal spine. As it courses along the floor of the canal it is tightly attached to the vertebral bodies and to the intervertebral disks it crosses. The ventral longitudinal ligament runs along the ventral aspect of the vertebral bodies. The interarcuate ligaments form between the arches of adjacent vertebrae and close of the vertebral canal dorsolaterally. The intercapital ligaments are present in the thoracic spine and run across the floor of the vertebral canal from one rib head to the opposite one. This ligament is often absent at T1, T11, T12 and T13.

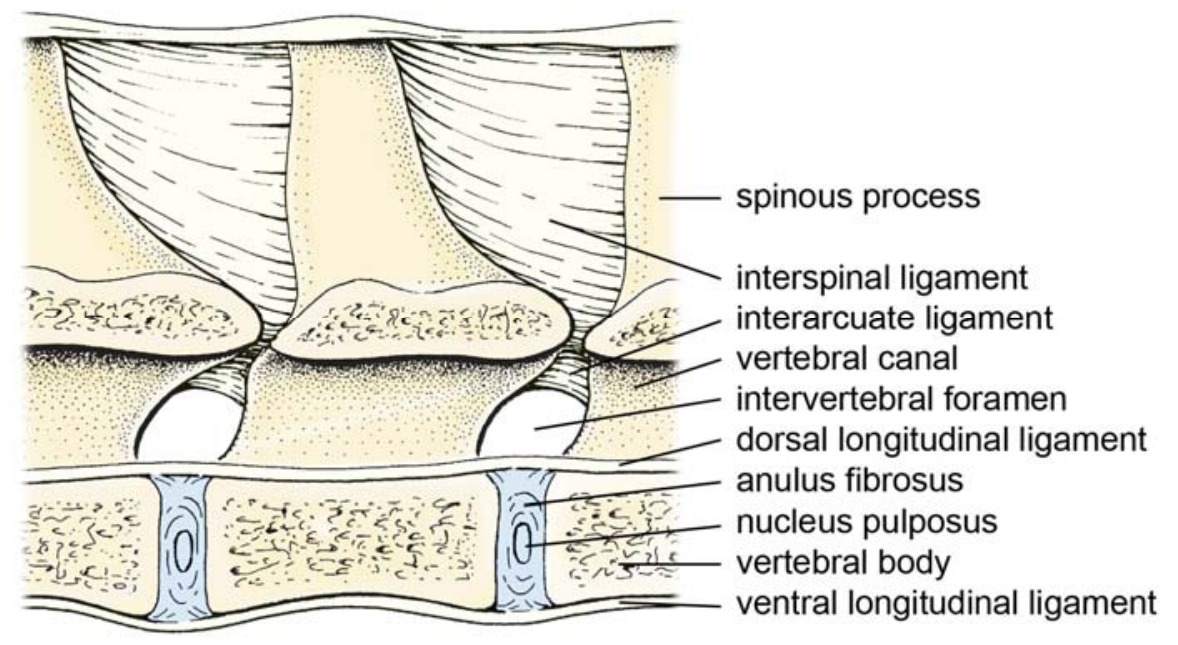

Figure 4: Schematic drawing of sagittally sectioned lumbar vertebrae of a dog.

Modified from König, Liebich. Anatomy of domestic mammals. 3rd edition. Schattauer, 2006. 
While vertebrae of the different anatomic locations have similar bone structure in general, their shape and size is quite different. For example, the vertebral bodies of the cervical vertebrae are much narrower compared to the lumbar spine; articular processes are larger and more horizontally oriented in the cervical spine compared to the thoracic and lumbar vertebrae; and cervical vertebrae C2-C6 have a large transverse foramen bilaterally, which is not present in any of the other vertebrae (Figure 5), cranial thoracic vertebrae have a very long spinous process but much smaller transverse processes. Along with these and other inherent differences, vertebrae can be anomalous and not display the typical structures. Also, there are breed-associated differences making it difficult to generalize shapes and sizes for different vertebrae.
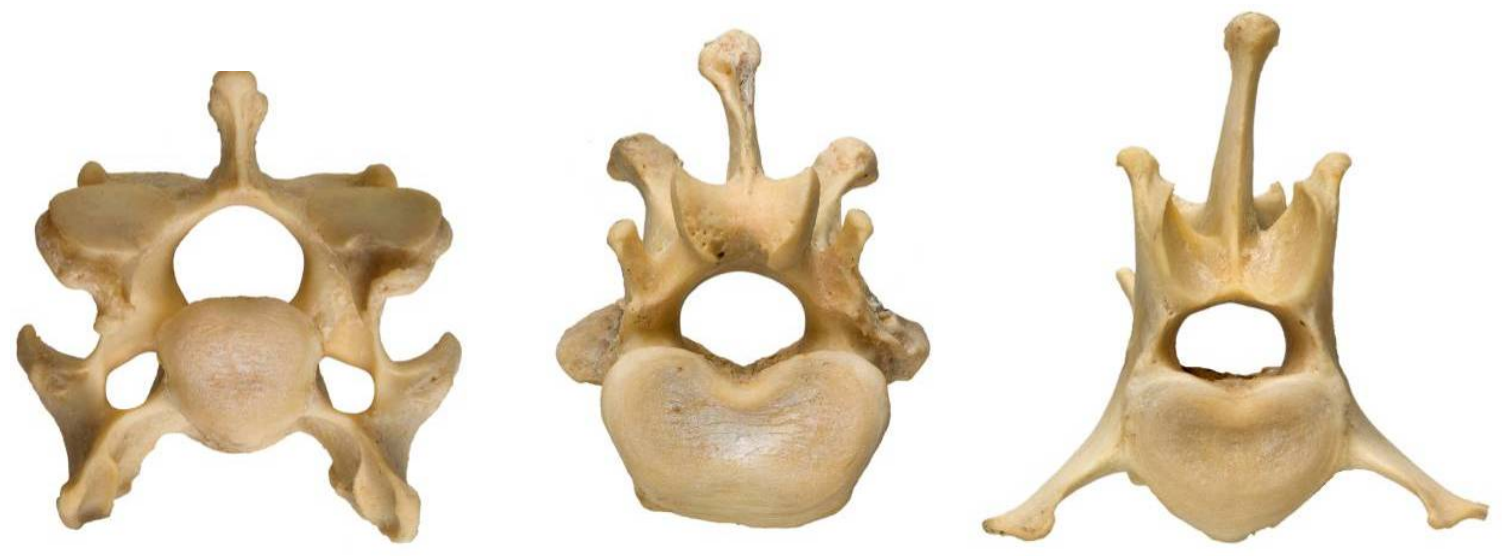

Figure 5: Specimens of vertebra C6 (left), T12 (center) and L3 (right) of a medium sized dog (25 kg) showing anatomic differences between vertebrae of different locations within the vertebral column.

Vertebral Column Biomechanics

While the amount of movement is limited between only 2 vertebrae, the vertebral column as a whole is flexible enough to allow movement in different directions. The direction of inclination of the articular processes plays an important role in restricting mobility. Fractures and luxations have been reported to occur more likely in areas of the vertebral column where more mobile and immobile 
segments articulate ${ }^{19-21}$. Examples are the atlanto-occipital joint, atlanto-axial, caudal cervical to thoracic spine, thoracolumbar junction and lumbosacral articulation. In general, the thoracic vertebral column has decreased movement due to the inherent stability provided by the rib cage and thoracic musculature.

Pathologic Vertebral Column Instability

Instability of the vertebral column can be the result of many conditions such as trauma, congenital anomalies, degenerative changes, and pathologic processes such as neoplasia and infection.

Traumatic vertebral column injury is often due to vehicular accidents. High energy impact can lead to excessive flexion, extension, rotation, compression or bending of the vertebral column. This may cause vertebral fractures and/or subluxation/luxation. The type of injury may reveal the traumatic force behind it, for example: vertebral endplate fractures are usually caused by hyperflexion and articular process fractures are often due to rotational or lateral bending forces. Apart from bony injury and disruption of alignment, trauma can also lead to myelopathy through disk extrusion, hemorrhage, and spinal cord contusion. Fractures or luxations rarely occur between thoracic vertebra 1 and 10; however, they commonly affect the thoracolumbar junction, lumbar spine and lumbosacral junction. The need for vertebral column stabilization is based on the injury/pathology present and how unstable the spine has become. Vertebral trauma is often classified using the 3-compartment model modified by Shores ${ }^{21,22}$ where each vertebra is divided into a dorsal (spinous process, lamina, pedicles and articular processes), middle (dorsal longitudinal ligament, dorsal portion of the anulus fibrosus and vertebral body) and ventral compartment (remaining intervertebral disk and vertebral body, ventral longitudinal ligament. It is assumed that injury to 2 out of the 3 compartments results in vertebral column instability.

Caudal cervical spondylomyelopathy (Wobbler's syndrome) commonly affects large and giant breed dogs such as the Doberman pinscher and Great 
Dane. While the exact pathophysiology has not been determined, many believe that underlying instability causes soft tissue and bone hypertrophy and disk degeneration. This then leads to spinal cord compression and chronic progressive myelopathy. One of the treatment options for suspected cervical instability due to Wobbler's is intervertebral distraction and stabilization. The goal is usually to achieve bony fusion across the affected intervertebral articulation for longterm stability, with implants providing short term fixation.

Lumbosacral disease is a chronic progressive disease typically afflicting middle aged to older large breed dogs with a predilection for German shepherd dogs. The disease is characterized by compression of the cauda equine within the vertebral canal and of spinal nerves within the intervertebral foramina. Disk degeneration with anular hypertrophy, osteophyte formation and joint capsule hypertrophy associated with the articular processes, and ligamentous hypertrophy especially of the interarcuate ligament are components of compressive tissue. Ventral subluxation of the sacrum can be found as well, leading to the suspicion that chronic instability of the LS articulation may be the underlying cause of LS disease. Therefore, one possible surgical option is stabilization of the lumbosacral articulation.

Atlantoaxial instability affects toy and miniature dog breeds most commonly and is often due to congenital malformations of the dens leading to abnormal biomechanics and ultimate subluxation of the AA joint. Depending on the severity of pain and neurologic deficits, surgical stabilization can be pursued.

Bone destruction secondary to infectious or neoplastic processes can cause pathologic vertebral column instability. Bone lysis associated with diskospondylitis, an infection of two adjacent vertebral endplates and the intervertebral disk, can lead to structural weakness and either fracture of the affected bone or collapse of the affected disk space with subluxation. Bone lysis is also the underlying cause for pathologic fractures associated with bony neoplasia such as osteosarcoma or 
plasmacytoma. Part of the therapeutic plan for infection or neoplasia-induced instability may be vertebral column stabilization.

\section{Surgical Anatomy and Approaches}

The vertebral body offers the largest amount of bone and ideally is used for implant placement. Bicortical implants also engage the vertebral pedicle, either at their entry or exit of the bone. Cervical vertebral column stabilization is most often performed via a ventral approach using the vertebral body and possibly transverse processes for implant placement. Most thoracolumbar stabilization techniques aim for placement of implants into the pedicle and vertebral body via a dorsal or lateral approach since gaining access to the ventral spine would require an intrathoracic or intraabdominal approach in most cases. Also, the pedicle is often narrow and the target area small, allowing for implants to be placed suboptimally (either into the spinal canal or too far laterally with poor bone purchase). Anatomic differences between each vertebra of the same animal but also between different breeds make standardization of implant placement difficult (

Figure 6).
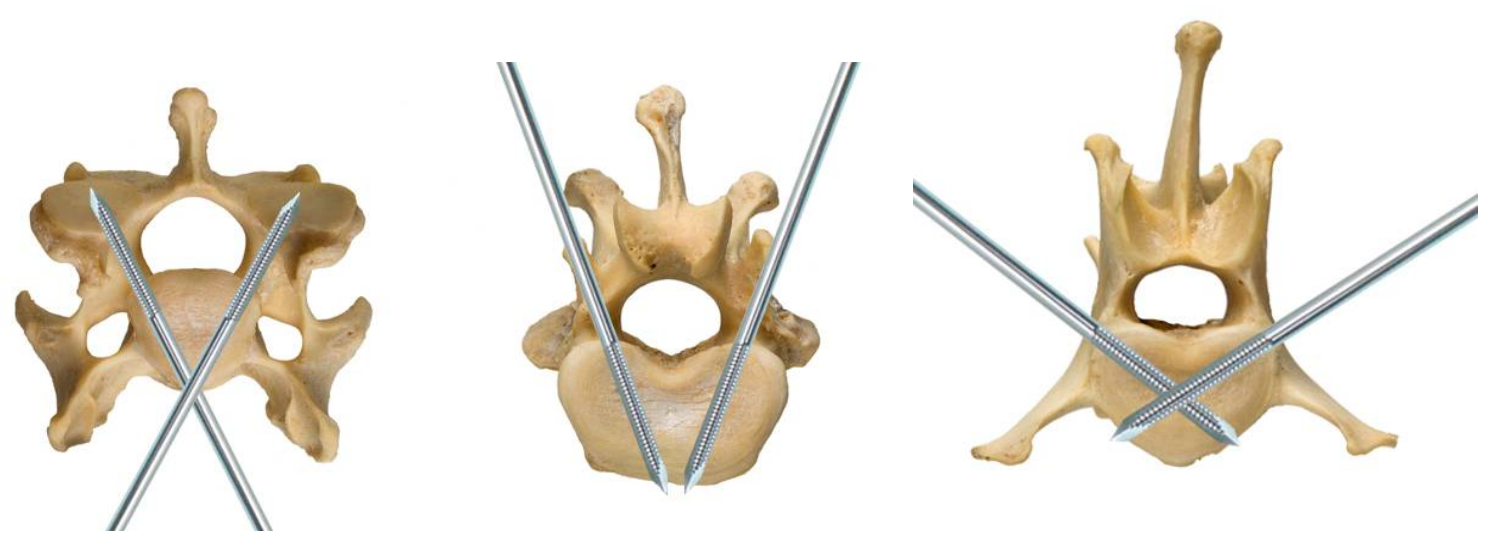

Figure 6: Canine specimens of vertebra C6 (left), T12 (center) and L3 (right) showing traditional bicortical placement of pins through vertebral body and pedicle. 


\section{Implant Selection}

Due to the limited amount of bone of the vertebral column, most implants are inherently close to the spinal cord. Bicortical pins and PMMA are a commonly applied technique for medium and large breed dogs that suffer from vertebral column instability in the cervical and thoracolumbar spine. Depending on the degree of instability, these pins can be placed in either one or two vertebrae cranial and caudal to the injury as well as on both sides of each vertebra. Positive profile pins improve pullout resistance and decrease migration compared to smooth pins. The use of pins is preferable over similar sized screws as the core diameter of a pin is larger, making it a stronger implant. Cancellous screws are generally avoided as they are significantly weaker than cortical screws due to the smaller core diameter compared to similar cortical screws. The largest pin or screw possible should be used.
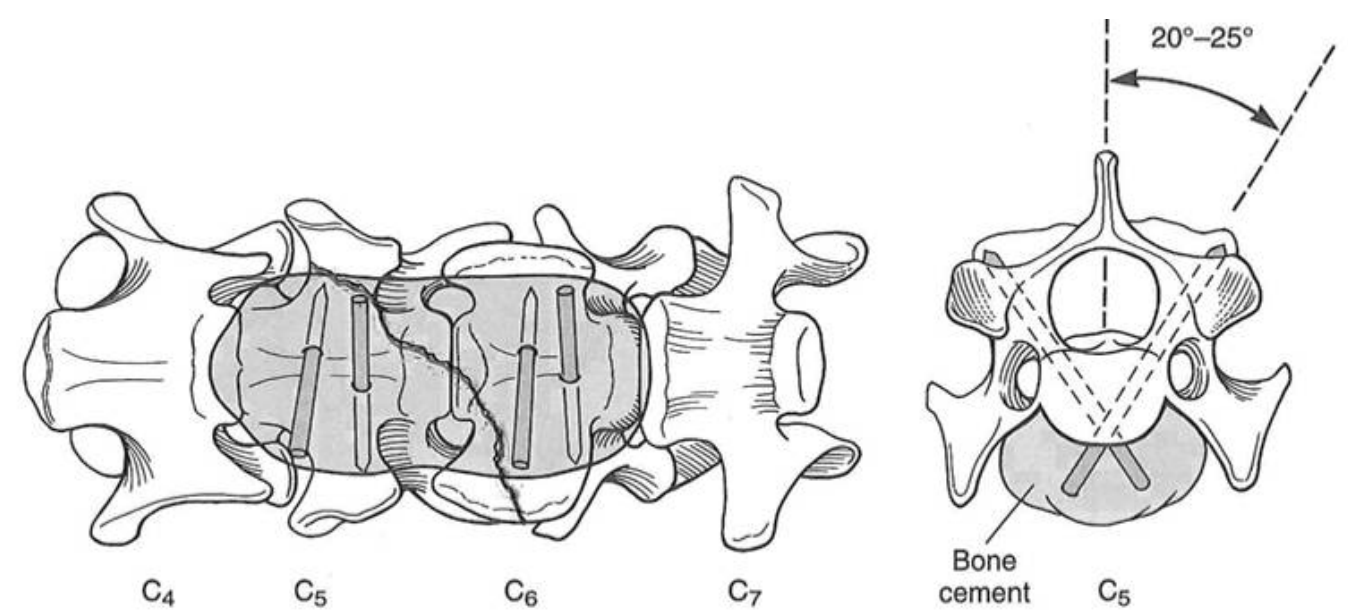

Figure 7: Example of a pin/PMMA construct in the cervical vertebral column.

Illustration from Fossum's Textbook of Small Animal Surgery, $2^{\text {nd }}$ edition, 2002, Mosby. 

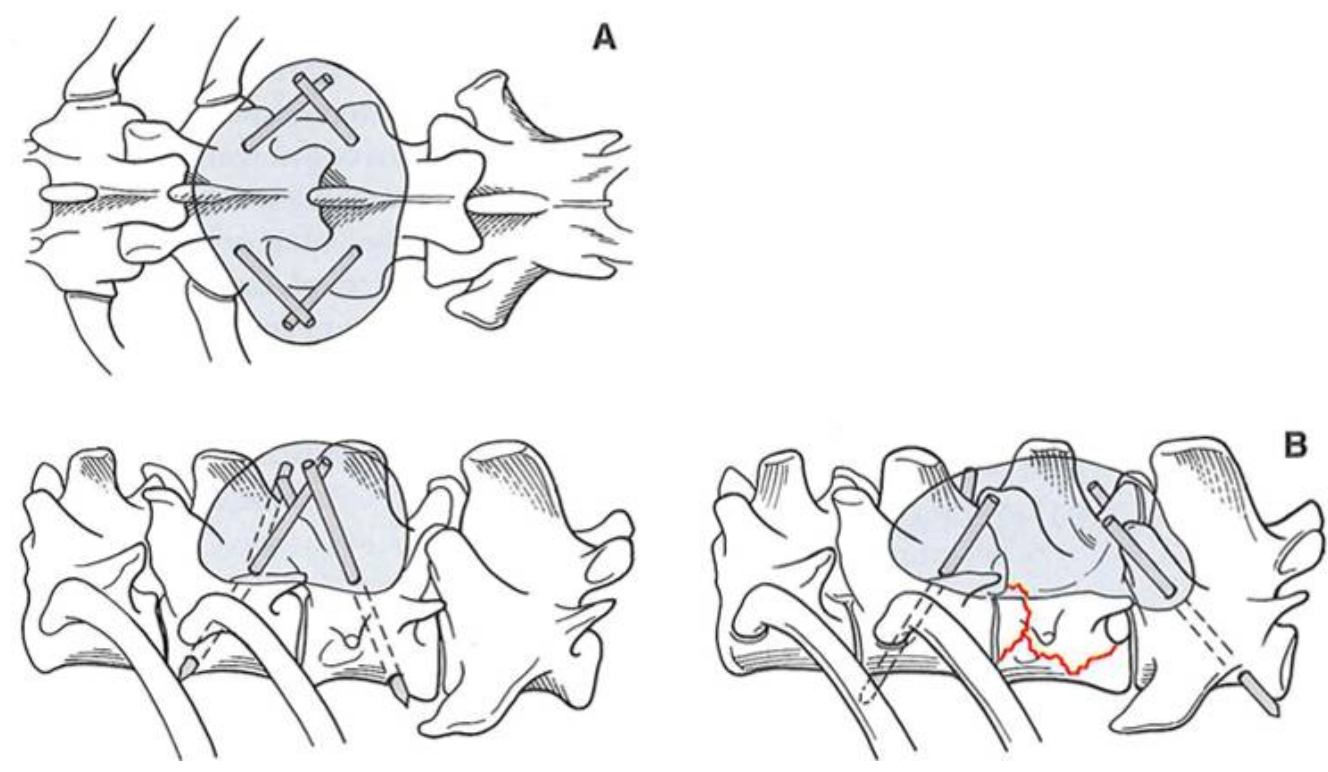

Figure 8: Example of a pin/PMMA construct in the TL vertebral column. A: fixation of an intervertebral articulation. B: fixation of an unstable vertebra. Illustration from Fossum's Textbook of Small Animal Surgery, $2^{\text {nd }}$ edition, 2002, Mosby.

While bicortical implants have biomechanical advantages they may cause damage to the vertebral vessels or nerve roots in the cervical and aorta or vena cava caudalis in the thoracolumbar spine. Corlazzoli evaluated the risk of vertebral canal violation in the cervical spine using angles of 30 to 40 degrees from vertical. ${ }^{18}$ Due to the unacceptably high risk of vertebral canal violation, bicortical implant placement in the traditional way is no longer recommended and the use of monocortical implants should be considered in the cervical vertebral column. Alternatively, implants can be placed into the base of the transverse process. With the introduction of implants with locking mechanism, implant loosening is decreased and lower profile implants (i.e. SOP) may take the place of fixation using PMMA. This would decrease soft tissue dissection and improve soft tissue closure. General guidelines for screw placement should still be applied. The use of stabilizing procedures that do not require placement of implants near the spinal cord are often limited to small sized dogs or cats (i.e. lubra plate, spinal stapling, 
Figure 9). Due to their high failure rates and inadequate stabilization, they are not recommended in larger dogs.

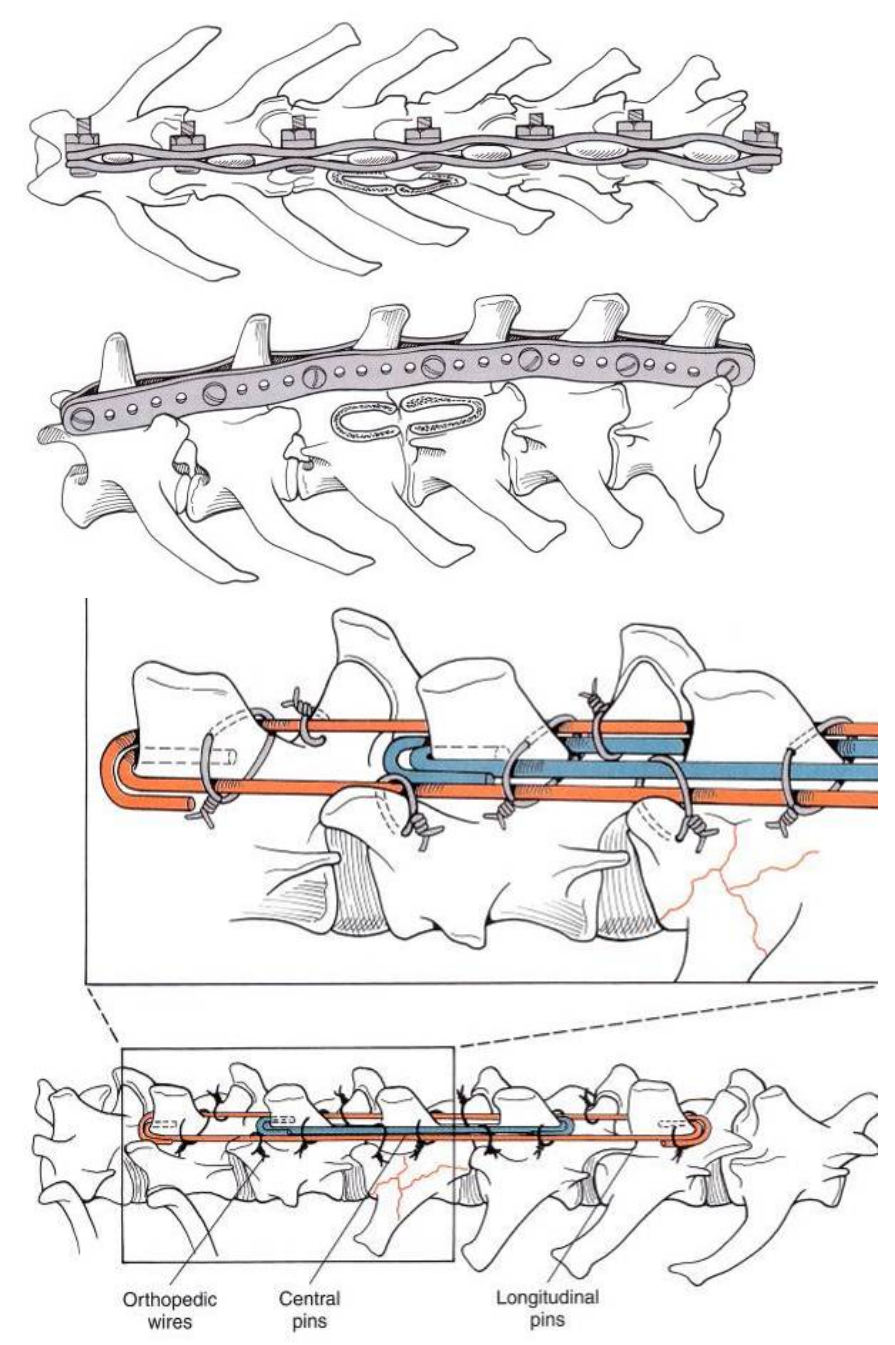

Figure 9: Left - lubra plate applied to the lumbar spine; right - spinal stapling used at the thoracolumbar junction. Illustration from Fossum's Textbook of Small Animal Surgery, $2^{\text {nd }}$ edition, 2002, Mosby.

\section{Landmarks and Insertion Angles}

Most studies evaluating insertion angles are based on CT studies were implants have been superimposed over a transverse image or lines have been drawn to mimic implant path. Watine ${ }^{14}$ determined implant corridors for $\mathrm{C} 2-\mathrm{C} 7$ and T10-S1 from 207 vertebral images of 35 dogs. Images of 9 to 16 dogs per vertebra 
were available for assessment. Vascular structures in proximity to these corridors were also identified (Figure 10).

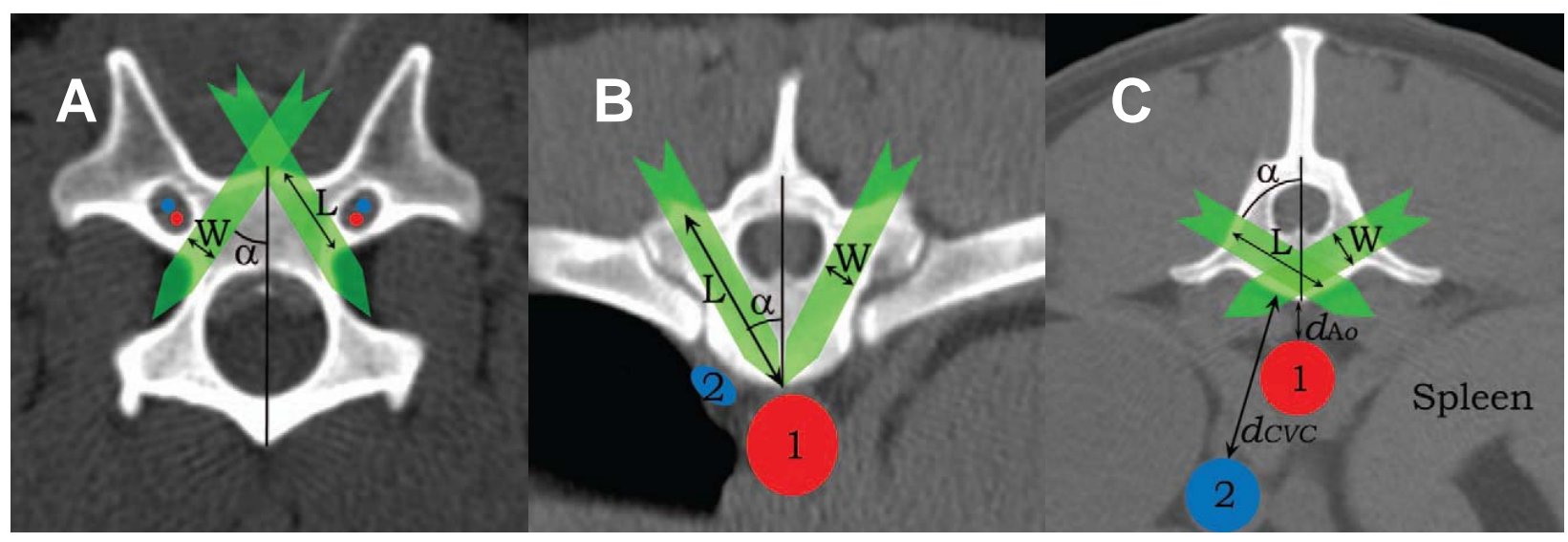

Figure 10: Transverse computed tomography section C6 (A), T11 (B) and L1 (C) showing recommended widths and lengths of implant insertion corridors and angle between insertion corridor and sagittal plane. Proximity to important vascular structures is evident ( $A$ : vertebral artery and vein in transverse foramen; $B$ : 1 Aorta, 2 Azygos vein; C: 1 Aorta, 2 Caudal vena cava). Modified from Watine ${ }^{14}$, JSAP 2006.

Ideal insertion angles and landmarks for bicortical implants in different anatomic locations along the canine vertebral column are summarized in Table 1. Inherent complications associated with implant placement include penetration of implants into the vertebral canal with the possibility of iatrogenic injury to local neural and vascular structures.

It is prudent to note that reported ideal implant angles are based on placement that provides the most bone purchase without penetration into the canal. Since these are mostly generated through imaging studies, angles do not take the surrounding soft tissues into account, which can impair implant placement significantly. 
Table 1: Recommended insertion angles ${ }^{14}$ and landmarks for bicortical spinal implants.

\begin{tabular}{|c|c|c|}
\hline Location & Insertion angle from vertical & Landmarks for insertion \\
\hline C2 & $50^{\circ}\left(45^{\circ}-60^{\circ}\right)$ & \multirow[t]{6}{*}{ Ventral midline } \\
\hline C3 & $37.5^{\circ}\left(33^{\circ}-45^{\circ}\right)$ & \\
\hline C4 & $35.9^{\circ}\left(30^{\circ}-45^{\circ}\right)$ & \\
\hline C5 & $34.2^{\circ}\left(30^{\circ}-35^{\circ}\right)$ & \\
\hline C6 & $36.6^{\circ}\left(30^{\circ}-40^{\circ}\right)$ & \\
\hline$C 7$ & $47.5^{\circ}\left(45^{\circ}-55^{\circ}\right)$ & \\
\hline$T 10$ & $22^{\circ}\left(20^{\circ}-25^{\circ}\right)$ & \multirow{4}{*}{$\begin{array}{l}\text { Tubercle of ribs and base of accessory } \\
\text { process }\end{array}$} \\
\hline$T 11$ & $28^{\circ}\left(25^{\circ}-35^{\circ}\right)$ & \\
\hline T12 & $30.5^{\circ}\left(25^{\circ}-35^{\circ}\right)$ & \\
\hline$T 13$ & $44.5^{\circ}\left(40^{\circ}-45^{\circ}\right)$ & \\
\hline L1-L6 & $60^{\circ}\left(55^{\circ}-65^{\circ}\right)$ & $\begin{array}{l}\text { Junction between pedicle and transverse } \\
\text { process }\end{array}$ \\
\hline$L 7$ & $0^{\circ}$ & Base of cranial articular process \\
\hline S1 & $5^{\circ}\left(0^{\circ}-15^{\circ}\right)$ & Just caudal to cranial articular surfaces \\
\hline
\end{tabular}

Spinal Imaging

The most readily available postoperative imaging modality to assess implant position is conventional radiography. Whereas radiographs can correctly identify the number of implants and their general position, they may be inadequate for assessment of the precise location of implants relative to the vertebral canal. When implants are placed bilaterally, identification of vertebral canal penetration is further complicated by determining which implant is on the right and left of the vertebral column and this uncertainty increases the potential for error. Computed tomography (CT) provides cross-sectional images of regional anatomy with excellent bony detail; however, metal artifact may impair accurate assessment of implant position within a vertebra. ${ }^{23}$ In human medicine, CT is more accurate than conventional radiography for determination of pedicle screw position. ${ }^{24-28}$ In a single center retrospective study of dogs with vertebral trauma where CT was 
considered the gold standard, the sensitivity of radiography for detecting vertebral fracture and subluxation was $72 \%$ and $77.5 \%$, respectively. ${ }^{29}$ While magnetic resonance imaging allows for better evaluation of soft tissue structures such as the spinal cord compared to radiographs and $C T$, concerns exist about the interference of metal on the quality of images as well as heating or movement of traditional stainless steel implants. Studies are required to evaluate the accuracy of MRI in assessing vertebral implants as well as possible side-effects of using MRI on implants near the spinal cord.

Intraoperative Challenges and Injuries

While ideal insertion angles have been reported, the limited exposure can make it challenging to reproduce these in surgery. With an open approach, soft tissues tend to limit visibility of deeper located landmarks and make it difficult to adhere to the recommended angles (Figure 11). This often leads to implants being placed at a steeper angle than recommended despite best efforts. In the thoracolumbar spine the use of fluoroscopy and a closed application with insertion of pins through soft tissues seems to improve adherence to these recommended angles. ${ }^{2}$ Another common intraoperative challenge is limited visibility of landmarks for ideal implant insertion to prevent vertebral canal penetration but also avoid poor bony purchase. The combination of improper insertion point and angle can lead to catastrophic complications such as iatrogenic spinal cord damage or failure of fixation. Violation of the vertebral canal can cause extradural spinal cord compression or even penetration of the cord. Vasculature within the canal may be injured leading to hemorrhage and subsequent extradural compression or ischemia. Nerve roots may be lacerated or compressed either within the canal or at the intervertebral foramen. Depending on the level of injury (i.e. cervical or lumbar intumescence), nerve root injury may lead to significant neurologic deficits to a limb. The integrity of the intervertebral disk could be compromised leading to diskogenic pain, altered biomechanics (if it involves a disk space outside of the fixation area), and possibly delayed disk degeneration. In the cervical spine, 
penetration of the transverse foramen may lead to severe bleeding due to laceration of the vertebral artery.

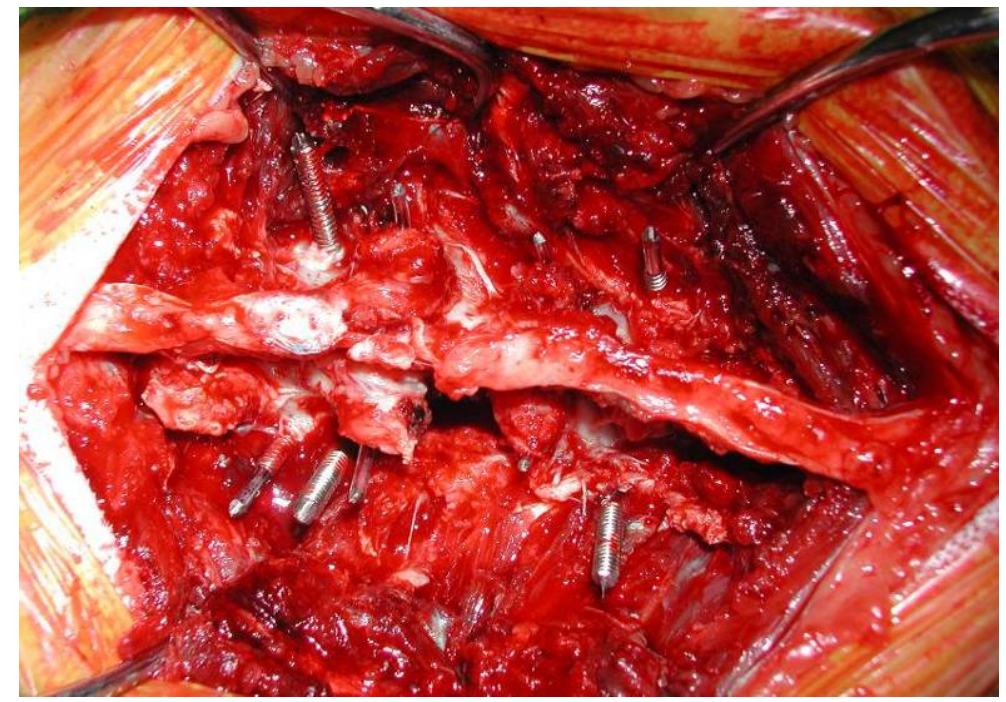

Figure 11: Intraoperative view of a thoracolumbar spinal fixation using pins and subsequently applied PMMA. Note the degree of soft tissue disruption but the remaining limited exposure of the vertebral column in this area.

The degree of canal violation has not been correlated with clinical signs in dogs or cats. Breed-specific differences in vertebral canal to spinal cord ratio have been documented with small dogs having a relatively larger spinal cord diameter compared to larger dogs, making the epidural space relatively smaller. This may lead to clinical signs with even slight compromise of the vertebral canal diameter, especially in a small breed dog. 


\section{Materials and Methods}

Entire vertebral columns of 12 mixed-breed dogs (weight range, $20-30 \mathrm{~kg}$ ) euthanatized for reasons unrelated to this study were collected, frozen $\left(-7^{\circ} \mathrm{C}\right)$, and then thawed immediately before evaluation. This population of dogs was chosen as they represented the average size in which pins and PMMA would be used clinically. Paraspinal musculature was removed from each vertebral column to allow observation of anatomic landmarks for recommended pin placement. The cervical and thoracic spine was separated between C7/T1 or T1/T2. Smooth 5/64 inch or $1 / 8$-inch Steinmann pins (IMEX ${ }^{\mathrm{TM}}$ Veterinary Inc, Longview, TX) were inserted bilaterally in vertebral bodies C2-C7 and T10-L7. Thoracic vertebra 1 - 9 were not evaluated because fractures in this location are uncommon (with fractures being a primary indication for the pins and PMMA technique) and often do not require surgical stabilization. ${ }^{30}$ The atlantoaxial joint was also excluded because the implant type studied would not be used in C1. All pins were inserted by one person (BFH).

Insertion angles for each vertebra were based on published recommendations ${ }^{12-14,16,18}$ and were intended to be within the following ranges: $\mathrm{C} 2$ :

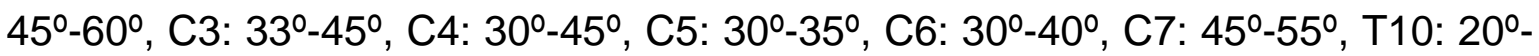

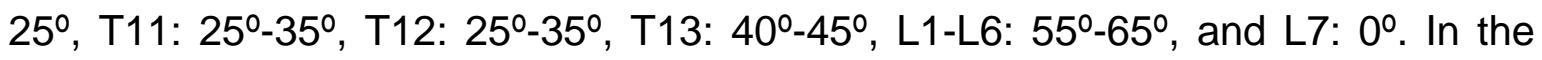
cervical vertebral column, pins were inserted from the ventral aspect into each vertebral body of $\mathrm{C} 2-\mathrm{C} 7$. Four pins were placed in each vertebral body (2 into the cranial and 2 into the caudal metaphysis) except in C2 where only 2 caudal pins were placed (Figure 12). The pin entry point was close to or on the ventral midline. 


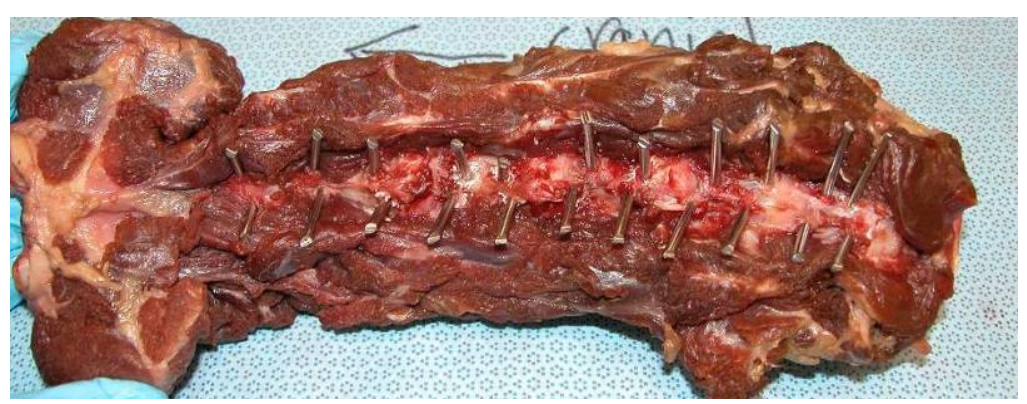

Figure 12: Ventral aspect of a canine cadaveric cervical spine with pins placed in vertebral bodies $\mathrm{C} 2-\mathrm{C} 7$.

In the thoracic vertebral column, pins were placed bilaterally from the dorsolateral aspect into each vertebral body of T10 - T13. Two pins were generally placed in each vertebra, unless the size allowed placement of 4 pins ( 2 cranial, 2 caudal within vertebral body, Figure 13). Landmarks for insertion included the tubercle of the ribs and the base of the accessory process. In the lumbar vertebral column, pins were placed bilaterally from the dorsolateral aspect into each vertebral body of $L 1$ - L7. Four pins were placed in each vertebra, except L7 where only 2 pins were placed. The insertion landmark for L1-L6 was the junction between pedicle and transverse process and for $L 7$ the base of the cranial articular process.

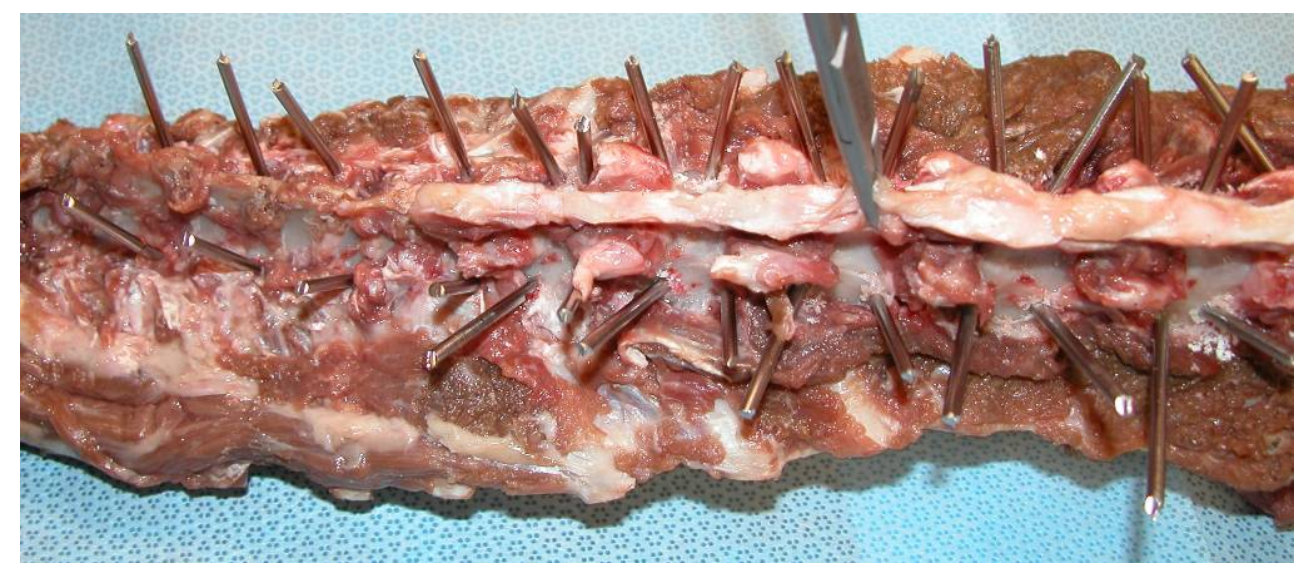

Figure 13: Canine cadaveric thoracolumbar spine with pins placed in vertebral bodies bilaterally from dorsolateral to ventromedial. 
Whereas these landmarks and published insertion angles were considered for pin placement, no effort was made to prevent inadvertent vertebral canal penetration as the study required both pins violating the canal and not violating the canal. Actual pin positions were unknown until study end when the vertebral columns were anatomically prepared.

Clinically, PMMA is applied to the protruding pins on the dorsolateral aspect of the thoracolumbar and on the ventral aspect of the cervical vertebral column. To simulate coverage of pins by PMMA, 2 bars were molded and applied to the cadaveric specimens during radiographs. In the thoracolumbar vertebral column, 2 PMMA bars were applied dorsolaterally on each side of the spinous processes for both projections (laterolateral and dorsoventral) (Figure 14). In the cervical vertebral column, one PMMA bar was placed ventrally over the pins on the ventrodorsal projection (Figure 15). The PMMA bar was not used for the lateral projection of the cervical spine because PMMA is placed ventral to the vertebral bodies and should therefore not interfere with the evaluation of the vertebral canal as it is not superimposed. The cement mantle had an average diameter of $2 \mathrm{~cm}$ and was kept as uniform as possible. For CT, the PMMA bars were not applied because the bone cement was not expected to influence the evaluators' ability to assess the vertebral implants as it did not involve the vertebral canal nor create an artifact. 


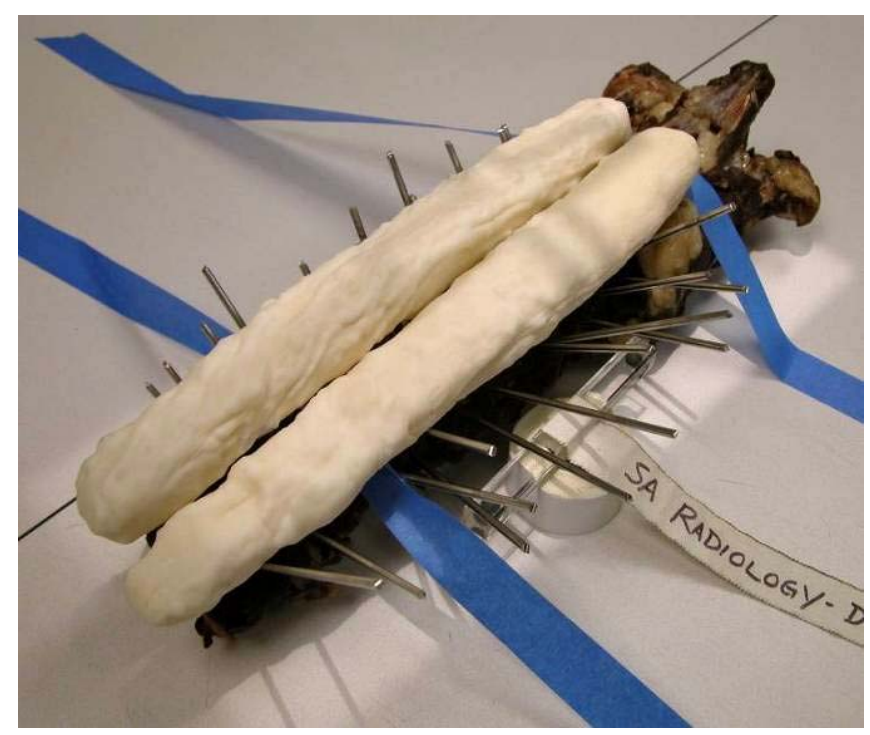

Figure 14: Two PMMA bars applied dorsolaterally to a cadaveric thoracolumbar spine.

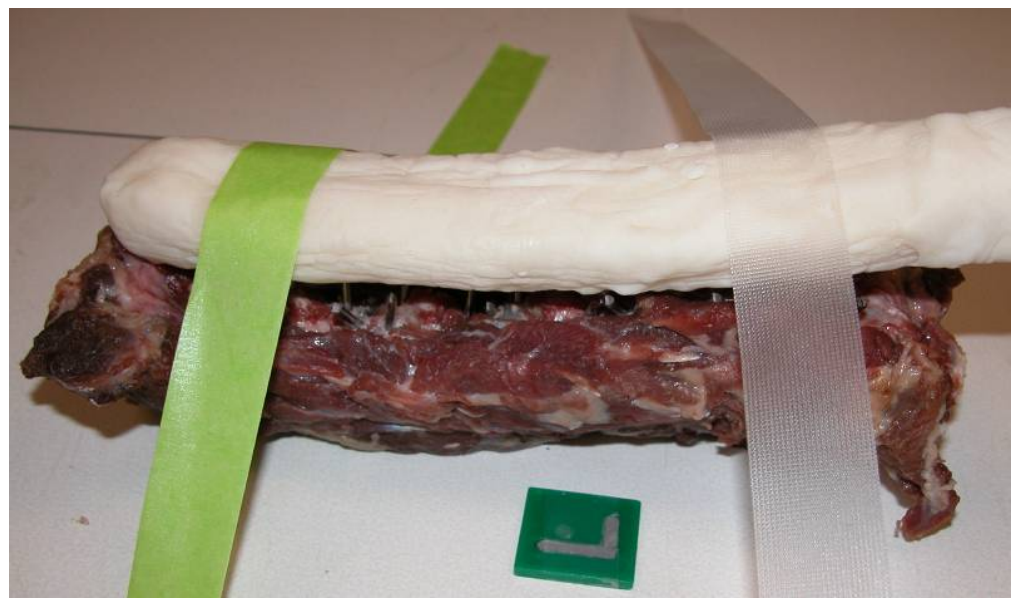

Figure 15: One PMMA bar applied ventrally to a cadaveric cervical spine.

Imaging

Standard lateral and ventrodorsal (cervical) or dorsoventral (thoracic and lumbar) radiographs of the cervical and thoracolumbar vertebral columns were obtained. Steinmann pins were labeled on each radiographic view independently so that individual pin identity was not clearly noted across views (Figure 16). 

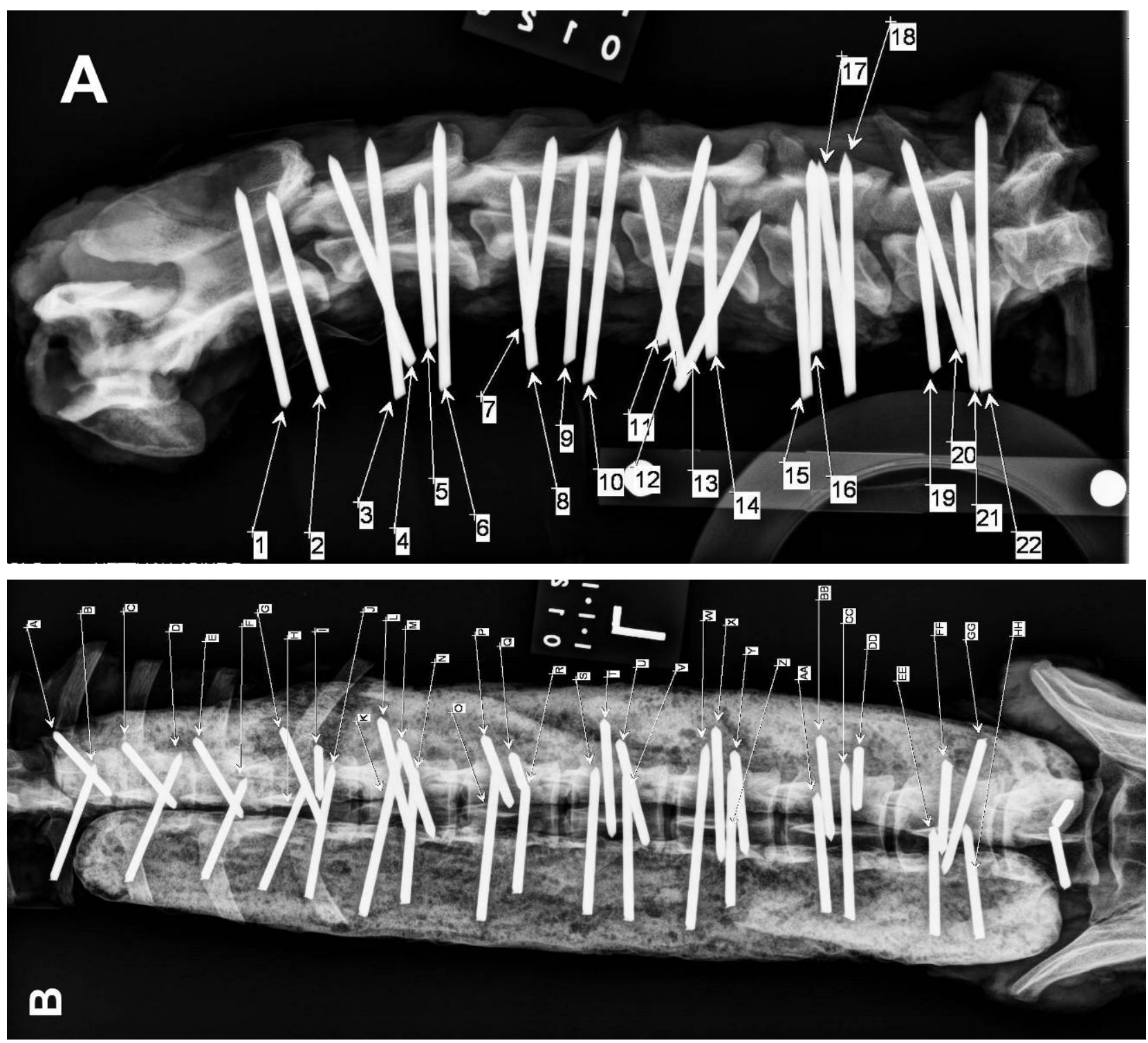

Figure 16: A) Lateral radiograph of a cervical and B) dorsoventral radiograph of a thoracolumbar vertebral column. PMMA bars are applied to the thoracolumbar spine and individual pins are labeled.

CT images (GE LightSpeed QXI 4 Slice H1 Gantry) were obtained by contiguous $2.5 \mathrm{~mm}$ slice acquisition then reconstruction in a high spatial resolution (bone) algorithm (window width: 2000, window level: 400 ) at $1.25 \mathrm{~mm}$ slice thickness. These are standard settings to evaluate vertebral bone. Decreasing the slice acquisition to $1.25 \mathrm{~mm}$ would negatively affect the signal to noise ratio; a thinner slice produces a smaller volume with less signal and greater noise. 
Steinmann pin placement was evaluated on transverse images with respect to vertebral number (e.g., T10), side (left, right), and position within the vertebra (cranial, caudal). Digital viewing software (eFilm Workstation, Merge Healthcare, Milwaukee, $\mathrm{WI}$ ) was used to view both conventional radiographs and CT images. Image magnification and window level and width were adjusted according to individual evaluator preference. Two radiologists, 1 radiology resident, 2 small animal orthopedic surgeons, and 1 neurologist evaluated the images. All evaluators with the exception of the resident were board-certified in their specialty.

Three aspects were evaluated: 1) ability to correctly identify left and right implants on radiographs; 2) ability to correctly identify implant position in relation to the vertebral canal on radiographs; and 3) implant position on CT images. An implant was defined as 'out' if there was no distortion or penetration of the cortical bone of the vertebral canal. If a pin crossed an intervertebral foramen it was considered 'out' of the vertebral canal if it did not intrude into the diameter of the canal just cranial and caudal to the foramen. An implant was defined as 'in' if any part of it either penetrated or distorted the cortical surface of the vertebral canal. It was also 'in' if the implant was placed in the intervertebral foramen and violated the vertebral canal diameter just cranial and caudal to the foramen. Evaluators had to assess each implant with a commitment to either 'left' or 'right' and 'in' or 'out'. For each answer they selected a confidence level ranging from 50\% (completely unsure) to $100 \%$ (certain).

Each evaluator was asked to identify randomly selected pins as being 'left-' or 'right-' sided on both corresponding radiographic projections. If 2 or 3 pins were present in a vertebra then only 1 pin was randomly chosen from each projection. If 4 pins were present, 2 pins were randomly selected for evaluation. Both radiographic views were available; however, pins were not matched for labeling, requiring interpreters to attempt to determine corresponding pins on respective views. Evaluators were then given both projections of the cervical and thoracolumbar vertebral columns with identification of corresponding left and right 
pins and all pins were evaluated for implant position in relation to the vertebral column ('in' or 'out').

Finally, each evaluator was provided access to the entire CT series of the cervical and thoracolumbar vertebral columns. Again, every implant was evaluated for being 'in' or 'out' of the vertebral canal. In addition, if a pin was labeled as 'in', evaluators were asked to further define the penetration into the vertebral canal as 'partial' (only part of pin within vertebral canal) or 'complete' (the entire circumference of the pin within vertebral canal; Figure 17). Images could also be reformatted into orthogonal planes if desired. Whereas any plane could be used for evaluation, data were recorded only for transverse images.

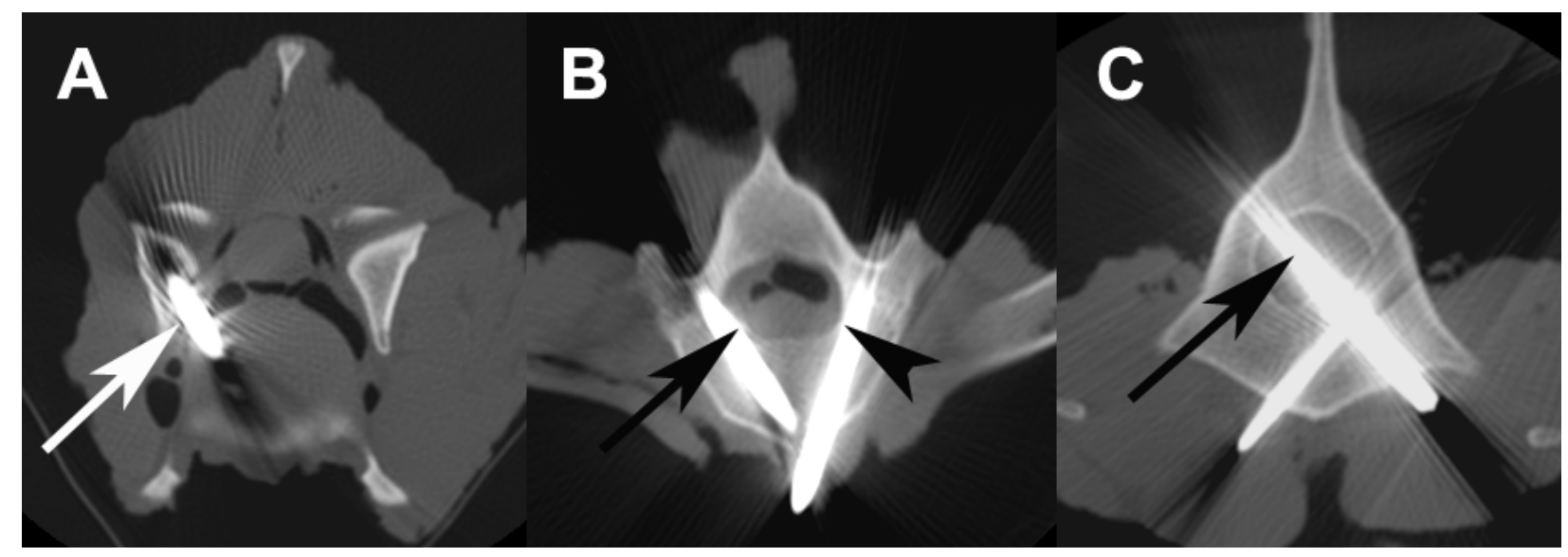

Figure 17: A) Axial CT images of $C 4$ with pin in foramen but not compromising vertebral canal (white arrow); B) T12 vertebra with 1 pin partially penetrating vertebral canal (black arrow) and 1 pin not penetrating the cortex (black arrow head); L4 vertebra with pin completely penetrating vertebral canal (black arrow).

After collection of imaging data was completed, each vertebral column was disarticulated and all vertebrae were assigned identifiers. Then, all soft tissues were dissected away from each vertebra leaving only the bones and pins remaining. This allowed visual inspection of the vertebral canal and was considered to be the optimal method to evaluate canal penetration. Actual canal penetration was unknown before this procedure. Findings of this direct visual 
examination were considered the gold standard for estimating accuracy (Figure 18).
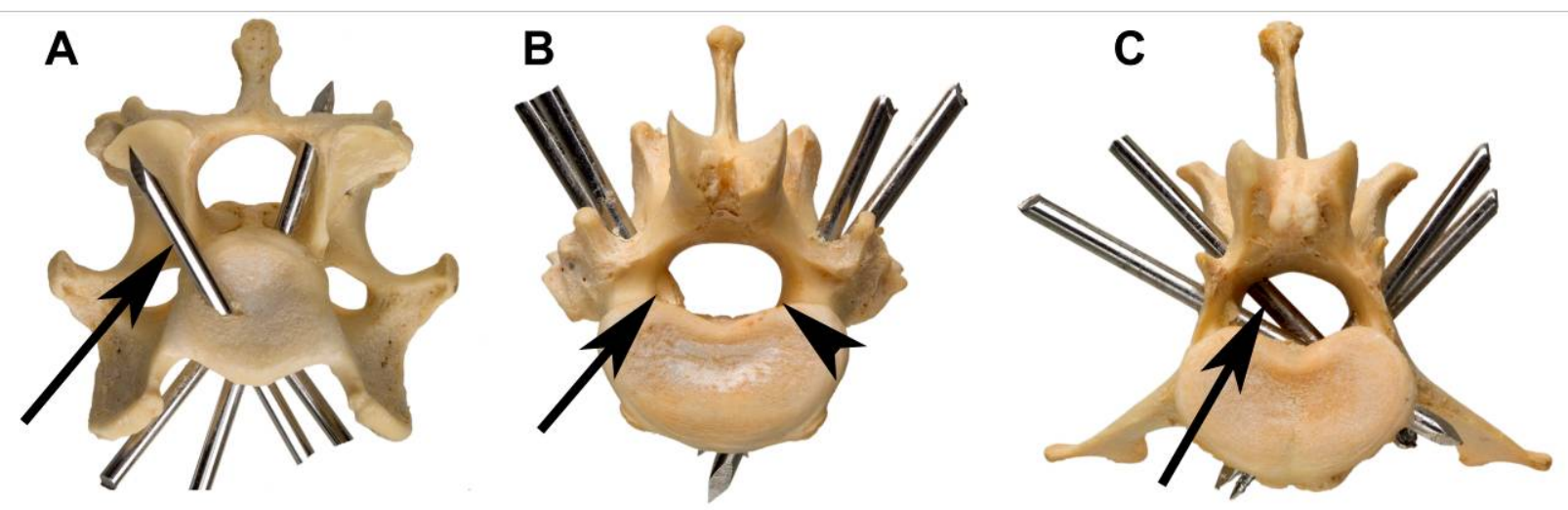

Figure 18: A) Caudal view of C4 vertebra with pin in foramen but not compromising vertebral canal (black arrow - same as Fig 2A); B) caudal view of T12 vertebra with 1 pin partially penetrating canal (black arrow - same as Fig 2B) and normal inner vertebral cortex (arrow head); C) caudal view of L4 vertebra with pin completely penetrating canal (black arrow - same as Fig 2C).

\section{Statistical Analysis}

The proportion of correct identifications of left and right pins was estimated overall and by the subsets of location (cervical versus thoracolumbar vertebrae), evaluator (neurologist/surgeon versus radiologist), and evaluator confidence level of determination (median and above versus lower confidence). The design effect ${ }^{31-}$ 33 was calculated as the variance of the clustered sampling (repeated determinations for the same pin) divided by the expected variance of simple random sampling. The variance for a clustered sample was estimated ${ }^{34}$ and used to adjust confidence intervals $(\mathrm{Cl})$ and statistical comparisons for the multiple observations performed on each individual pin. The proportion estimates for subgroups were statistically compared using $Z$ tests (comparison of proportions) incorporating the estimated design effects to adjust for clustering. ${ }^{35}$ Inter-rater agreement was estimated over all raters by calculating the Kappa statistic with its associated $\mathrm{P}$ value and $\mathrm{Cl}$ using previously reported formulas. ${ }^{35}$ 
The sensitivity for identification of a spinal pin as being in the canal was estimated as the proportion of correct determinations out of all pins observed to be in the canal based on direct visual examination. The sensitivity was estimated overall and by the subsets of degree of penetration of the canal (partial versus complete), location (cervical versus thoracolumbar vertebrae), evaluator (neurologist/surgeon versus radiologist), and evaluator confidence level of determination (median and above versus lower confidence). Sensitivity was also estimated within the subset of pins correctly identified as left or right by all evaluators and those in which at least 1 evaluator was incorrect. The specificity was estimated as the proportion of correct determinations out of all pins found to be outside the canal based on direct visual examination.

The specificity was estimated overall and by the subsets of location (cervical versus thoracolumbar vertebrae), evaluator (neurologist/surgeon versus radiologist), and evaluator confidence level of determination (median and above versus lower confidence). Specificity was also estimated within the subset of pins correctly identified as left or right by all evaluators and those in which at least 1 evaluator was incorrect. Overall accuracy was estimated as the proportion of pins correctly identified as being either in or not in the spinal canal.

The sensitivity and specificity of pin placement in the spinal canal was estimated independently for radiography and CT. Confidence intervals, inter-rater agreement, and statistical testing were calculated adjusting for the clustered data as described for left/right pin determination. Design effect estimation, inter-rater agreement analysis, and statistical testing was performed by manually entering equations into a commercially-available spreadsheet program (Microsoft Office Excel 2003, Microsoft Corporation, Redmond, WA). Significance was set at the 5\% level. Ninety-five percent $\mathrm{Cl}$ based on the continuity-corrected score method and adjusted for clustering were calculated using available software (Epi Info, version 6.04, CDC, Atlanta, GA). 


\section{Results}

Of 678 Steinmann pins placed in 12 canine cadaver vertebral columns, 245 were in the cervical spine and 433 in the thoracolumbar spine. Distribution of vertebral canal penetration was: 213 pins completely within the vertebral canal (entire circumference of pin), 236 pins partially within the canal, and 229 pins not violating the canal. For left/right accuracy, 459 pins were randomly selected from both radiographic views (lateral and ventrodorsal or dorsoventral) of the cervical (238) and thoracolumbar (221) vertebral column.

\section{Left/Right Accuracy}

Overall left/right accuracy was $93.1 \%(95 \% \mathrm{Cl}=91.9 \%-94.2 \%)$ and there was no difference between radiologists $(92.4 \% ; 95 \% \mathrm{Cl}=90.8 \%-93.7 \%)$ and non-radiologists $(93.9 \% ; 95 \% \mathrm{Cl}=92.5 \%-95.1 \%)$ in their ability to identify left from right pins $(P=.11)$. There was a significant difference for the $L / R$ determination between cervical $(91.9 \%, 95 \% \mathrm{Cl}=90.2-93.4)$ and $\mathrm{TL}(94.4 \%$, $95 \% \mathrm{Cl}=92.6-95.8 ; \mathrm{P}=0.03)$. The sensitivity $(95 \% \mathrm{Cl})$ of detecting pins within the spinal canal using radiography was 50.5\% (44.5\%-56.3\%) and $46.7 \%$ (40.9\%$52.5 \%)$ for pins that were correctly identified as being left or right by all evaluators and those in which at least 1 evaluator was in error, respectively. The specificity $(95 \% \mathrm{Cl})$ based on radiography was $79.6 \%$ (73.7\%-84.5\%) and $84.4 \%$ (77.3\%$89.7 \%$ ) for pins that were correctly identified as being left or right by all evaluators and those in which at least 1 evaluator was in error, respectively. Neither comparison was statistically significant $(P=.36$ and $P=.23)$.

Sensitivity and specificity of radiographic and CT assessment of implant position within the vertebral column are reported in Table 2 and Table 3 . The sensitivity of radiography was inversely related to the assessor's level of confidence (determinations made with higher confidence levels were less likely to be correct) 
but other determinations followed the expected pattern that higher confidence levels would be associated with greater accuracy (Table 4).

Table 2: Sensitivity of radiographic and computed tomography (CT) assessment of implant position within vertebral column.

\begin{tabular}{|c|c|c|c|c|}
\hline $\begin{array}{l}\text { Grouping } \\
\text { (No. pins) }\end{array}$ & $\begin{array}{l}\text { Radiograph* } \\
(95 \% \mathrm{Cl})\end{array}$ & $\begin{array}{l}\mathrm{CT} \\
(95 \% \mathrm{Cl})\end{array}$ & & $P$ value $\ddagger$ \\
\hline Overall $(n=449)$ & $50.7 \%(48.2,53.1)$ & $\begin{array}{l}93.4 \% \\
94.7)\end{array}$ & $(91.8$ & $<.0001$ \\
\hline Radiologists $(n=449)$ & $61.8 \%(59.2,64.5)$ & $\begin{array}{l}96.1 \% \\
97.0)\end{array}$ & (94.8, & $<.0001$ \\
\hline Non-radiologists $(n=449)$ & $39.5 \%(36.9,42.2)$ & $\begin{array}{l}90.6 \% \\
92.3)\end{array}$ & (88.7, & $<.0001$ \\
\hline Cervical spine $(n=164)$ & $57.6 \%(54.1,61.1)$ & $\begin{array}{l}91.7 \% \\
94.1)\end{array}$ & $(88.4$ & $<.0001$ \\
\hline $\begin{array}{l}\text { Thoracolumbar spine }(\mathrm{n}= \\
\text { 285) }\end{array}$ & $46.7 \%(43.5,49.9)$ & $\begin{array}{l}94.3 \% \\
95.7)\end{array}$ & $(92.5$ & $<.0001$ \\
\hline $\begin{array}{l}\text { Complete penetration }(n= \\
213)\end{array}$ & $63.6 \%(60.3,66.8)$ & $99.8 \%(99$. & , 100) & $<.0001$ \\
\hline Partial penetration $(n=236)$ & $39.0 \%(36.1,41.9)$ & $\begin{array}{l}87.5 \% \\
89.8)\end{array}$ & (84.8, & $<.0001$ \\
\hline
\end{tabular}

*Within radiography, radiologists versus non-radiologists, cervical versus thoracolumbar, and complete versus partial were significantly different $(P<.0001)$. †Within $\mathrm{CT}$, radiologists versus non-radiologists and complete versus partial were significantly different $(P<.0001)$ but cervical versus thoracolumbar was not $(P=$.094).

$\ddagger A l l ~ P$ values based on the $Z$ test to compare proportions adjusted for clustering. $\mathrm{Cl}=$ confidence interval. 
Table 3: Specificity of radiographic and computed tomography (CT) assessment of implant position within vertebral column.

\begin{tabular}{|c|c|c|c|}
\hline $\begin{array}{l}\text { Grouping } \\
\text { (No. pins) }\end{array}$ & $\begin{array}{l}\text { Radiograph* } \\
(95 \% \mathrm{Cl})\end{array}$ & $\begin{array}{l}\text { CT† } \\
(95 \% \mathrm{Cl})\end{array}$ & $P$ value $\neq$ \\
\hline Overall $(\mathrm{n}=229)$ & $82.9 \%(80.4,85.1)$ & $86.4 \%(83.5,88.8)$ & .049 \\
\hline Radiologists $(n=229)$ & $80.5 \%(77.3,83.4)$ & $80.1 \%(76.3,83.3)$ & .850 \\
\hline Non-radiologists $(n=229)$ & $85.3 \%(82.4,87.8)$ & $92.7 \%(90.5,94.5)$ & $<.0001$ \\
\hline Cervical spine $(n=81)$ & $84.0 \%(79.0,87.9)$ & $86.8 \%(82.2,90.4)$ & .330 \\
\hline $\begin{array}{l}\text { Thoracolumbar spine }(n= \\
\text { 148) }\end{array}$ & $82.3 \%(79.4,84.9)$ & $86.1 \%(82.3,89.3)$ & .085 \\
\hline
\end{tabular}

*Within radiography, radiologists versus non-radiologists was significantly different $(P=.018)$ but cervical versus thoracolumbar was not $(P=.528)$.

†Within $C T$, radiologists versus non-radiologists was significantly different $(P<$ $.0001)$ but cervical versus thoracolumbar was not $(\mathrm{P}=.797)$.

$\ddagger A l l ~ P$ values based on the $Z$ test to compare proportions adjusted for clustering. $\mathrm{Cl}=$ confidence interval. 
Table 4: Left - right determination for radiography and sensitivity and specificity of radiographic and computed tomography (CT) assessment of implant position within vertebral column compared to assessor's level of confidence.

\begin{tabular}{|c|c|c|c|c|c|c|c|}
\hline \multirow[b]{2}{*}{ Grouping } & \multicolumn{3}{|c|}{ Below median confidence } & \multirow[b]{2}{*}{$\mathrm{n}$} & \multicolumn{2}{|c|}{ Median and above confidence } & \multirow[b]{2}{*}{$P$ value* } \\
\hline & $\mathrm{n}$ & Proportion & $95 \% \mathrm{Cl}$ & & Proportion & $95 \% \mathrm{Cl}$ & \\
\hline Left/right determination & 861 & $85.8 \%$ & $83.2 \%, 88.1 \%$ & 1893 & $96.5 \%$ & $95.5 \%, 97.2 \%$ & $<.0001$ \\
\hline Sensitivity - radiology & 702 & $60.1 \%$ & $56.4 \%, 63.7 \%$ & 1992 & $47.3 \%$ & $44.5 \%, 50.2 \%$ & $<.0001$ \\
\hline Specificity - radiology & 495 & $69.5 \%$ & $65.2 \%, 73.5 \%$ & 879 & $90.4 \%$ & $88.1 \%, 92.4 \%$ & $<.0001$ \\
\hline Sensitivity - CT & 425 & $71.1 \%$ & $66.5 \%, 75.3 \%$ & 2269 & $97.5 \%$ & $96.5 \%, 98.3 \%$ & $<.0001$ \\
\hline Specificity - CT & 360 & $62.2 \%$ & $57.0 \%, 67.2 \%$ & 1014 & $95.0 \%$ & $93.1 \%, 96.3 \%$ & $<.0001$ \\
\hline
\end{tabular}

${ }^{*}$ Based on the $\mathrm{Z}$ test to compare proportions adjusted for clustering. $\mathrm{Cl}=$ confidence interval.

$\mathrm{n}=$ number of total assessments

The Kappa statistic $(95 \% \mathrm{Cl})$ was $0.78(0.75-0.80)$ for the overall determination of left and right pins and was statistically significant $(P<.001)$. The Kappa statistic $(95 \%$ $\mathrm{Cl}$ ) was 0.26 (0.24-0.28) for the overall determination of pins being in or out of the spinal canal based on radiologic assessment and was statistically significant $(P<.001)$. The Kappa statistic $(95 \% \mathrm{Cl})$ was $0.75(0.73-0.77)$ for the overall determination of pins being in or out of the spinal canal based on CT assessment and was also statistically significant $(P<.001)$. 


\section{Discussion}

Two recent studies have evaluated ideal pin placement angles in the canine cervical and thoracolumbar vertebral column. ${ }^{13,14}$ Whereas detailed knowledge of vertebral anatomy, pin insertion landmarks and angles will help to achieve the safest and most accurate implant placement, it is still possible to penetrate the vertebral canal. The true incidence of implant related canal penetration in clinical patients is unknown both in human and veterinary medicine. Because of the superimposition of structures on radiographs and the complex anatomy of the vertebral column, mental triangulation of the path of implants is difficult. Standard guidelines to aid in evaluation of spinal implants and their position in relation to the vertebral canal are not available. The superiority of CT over conventional radiographs in evaluating pedicle screw placement has been well documented in people ${ }^{24,26,28}$; however, even $\mathrm{CT}$ images do not provide a perfect method to identify vertebral canal violation. Our results clearly show that radiographic detection of vertebral canal violation by an implant placed in a fashion commonly used for vertebral column stabilization is difficult and that the sensitivity of CT is far superior to radiography in every aspect evaluated. Whereas the degree of partial canal penetration can still be misinterpreted, the sensitivity of detecting complete canal penetration was almost $100 \%$ with CT.

Limitations of this study are the use of vertebral columns with minimal soft tissue coverage rather than intact cadavers. Decreasing superimposition of tissues may improve evaluation of the vertebral canal on radiographs and cause accuracy measures to be biased in a positive direction. In a clinical setting, soft tissues and bone structures (i.e., sternum) surrounding the vertebral column can cause significant superimposition, likely obscuring the vertebral canal on radiographs and further decreasing the accuracy. The effect of paraspinal soft tissue on vertebral canal evaluation on CT; however, should be negligible due to the cross sectional acquisition of data, which eliminates superimposition. 
Another challenge of this study may be the number of pins inserted per vertebral column, which would not be placed clinically. Because our goal was to evaluate the relationship of a particular pin to the canal of its respective vertebra, the total number of pins per vertebral column was not an important consideration.

Because of financial constraints, smooth Steinmann pins were used rather than end-threaded positive-profile pins. Positive-profile pins have been shown to provide increased pull-out resistance compared with smooth pins and more rigid spinal fixation thereby decreasing the incidence of pin loosening and implant failure. ${ }^{36,37}$ Whereas use of positive-profile pins is generally recommended for spinal stabilization, their effect on accuracy as evaluated in this study is unknown. Also, for cost savings, PMMA bars were used to lay over the pins to mimic cement coverage rather than applying PMMA around implants as is performed clinically. Since the effect of superimposition was still provided this way, the PMMA bar usage was unlikely to negatively impact the study.

Another study limitation is that reported $P$ values were not adjusted for multiple comparisons and some of the $P$ values might not have been significant had adjustment been performed. Because all tests were performed based on a priori biological hypotheses (rather than post hoc), $\mathrm{P}$ values were not adjusted for multiple comparisons $^{38}$. Another important consideration is that the number of evaluators was small and might not accurately represent radiologists and non-radiologists in general. Therefore there is the potential for selection bias and more observers from several institutions would be required to evaluate this possibility. Reported results should be interpreted in conjunction with this limitation.

Before evaluating implant position relative to the vertebral canal, we determined how well evaluators were able to match left and right pins on both radiographic views. The value of correctly detecting canal violation is of little use if the incorrect pin is identified as the violator. When pins are placed in similar orientation and have no distinguishing features, correlating the obvious left or right pin on a ventrodorsal or 
dorsoventral view to the identical pin on the lateral view can be challenging. Inaccurate identification could lead to the removal of the wrong implant, which would allow for the continued presence of the problematic pin but also removal of a potentially well positioned and stable pin.

In this study, both radiologists and non-radiologists were able to correctly identify left and right implants in most cases (92.4\% and 93.9\%, respectively) with more accurate identification in the thoracolumbar compared with the cervical vertebral column (Table 4). This has likely nothing to do with differences in vertebral anatomy but rather with the angle and depth of implant insertion. In the thoracic spine, pins are usually more clearly identifiable as left and right on the DV or VD projections because they often have a longer end away from midline which is embedded in PMMA on each side. In the cervical spine, pins traverse the vertebra at greater length, with the pin crossing midline more equally on both ends. This, along with a slanted and pointed cut surface from a pin cutter, may give the PMMA embedded end the appearance of being the tip of the pin, thus confusing left from right pins (Figure 19). If pins cannot be identified as left or right on the VD or DV view, it is almost impossible to identify them by side on the lateral projection.
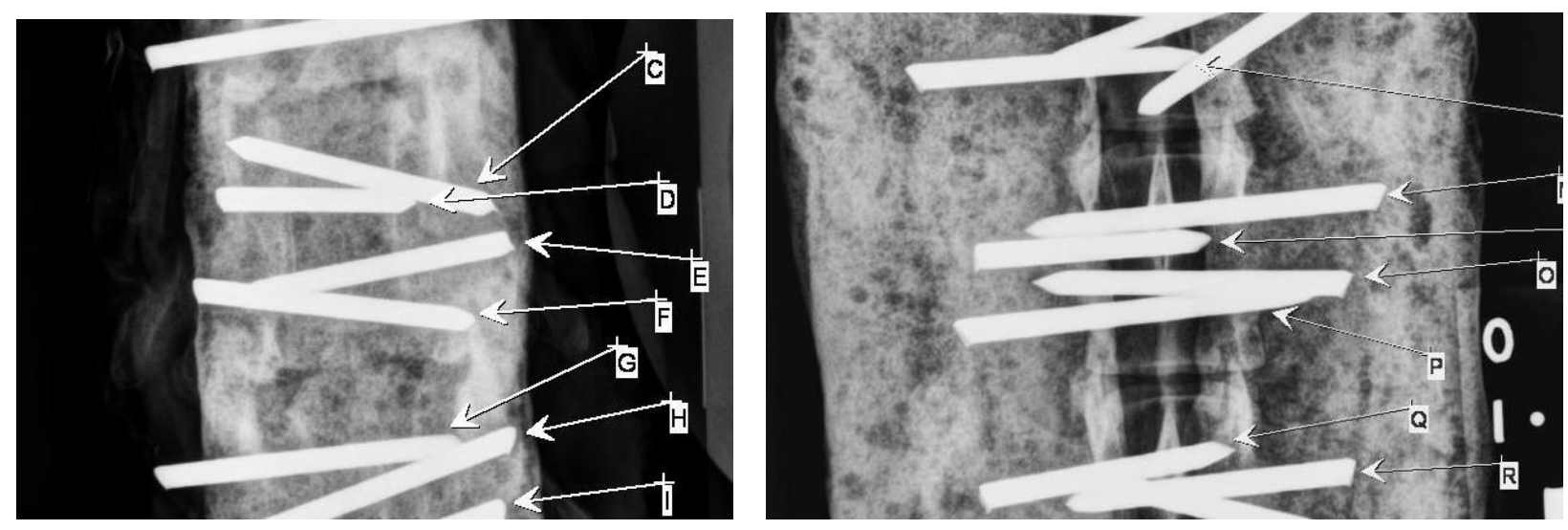

Figure 19: Section of a VD projection of the cervical spine (left) and of a DV projection of the lumbar spine documenting the difficulty to determine left and right pins with certainty, especially in the cervical spine. 
The repeatability of left/right determination was relatively high based on the Kappa statistic and this is further evidence of the usefulness of radiography for making this determination. A way to further improve left/right accuracy would be to use implants with distinguishing features. Ways to make implants more distinguishable could include notching or bending of pins, using pins of different length or size, or using pins with different thread coverage. Care has to be taken to not negatively influence implant stability by manipulating it after placement (i.e. bending a pin that has already been place into bone can weaken its pullout resistance).

Sensitivity of vertebral canal penetration based on radiography was poor $(50.7 \%)$. The type of evaluator, location within vertebral column, and degree of canal penetration significantly affected sensitivity, with radiologists having a higher sensitivity than non-radiologists, and improved sensitivity detecting implant penetration in the cervical spine when there was complete penetration. Even with complete canal penetration, sensitivity of radiography was only $63.6 \%$. Whereas it may be of lesser consequence to the patient to miss minimal canal intrusion by an implant, it certainly is not acceptable to misjudge complete penetration of a pin into the vertebral canal. Specificity of radiography was $82.9 \%$ with no difference in anatomic location. Interestingly, non-radiologists had a higher specificity than radiologists (Table 2).

Higher confidence level did not correlate with a correct answer of 'in' or 'out' with radiographic assessment, which illuminates the difficulties associated with the mental three-dimensional reconstruction. A weakness of this study is that because of cost limitations, only 2 orthogonal projections were made for each region (cervical and thoracolumbar spine). It is possible that beam divergence may have affected evaluator accuracy in those vertebrae at the periphery of each image. The measured Kappa statistic (0.26) suggests poor repeatability of radiographic assessment for determining canal violation. In a clinical setting if a larger area of interest is present, multiple radiographs would be obtained to prevent beam divergence. The value of oblique radiographic projections as not been evaluated in conjunction with canine vertebral column implants. 
CT was significantly more sensitive than conventional radiography for determination of implant position relative to the vertebral canal (93.4\%). As with radiographs, radiologists had significantly higher sensitivity than non-radiologists, and complete penetration was significantly more likely to be detected than partial. Anatomic location, however, did not significantly affect sensitivity (Table 2). CT was also significantly more specific than radiography and within the different groups nonradiologist had a significantly higher specificity than radiologists. The repeatability of CT for determining canal violation was relatively high (Kappa $=0.75)$ and is further evidence of its benefit over radiography.

The higher specificity for non-radiologists with both imaging techniques is unusual (Table 3). It may reflect the radiologists' effort in evaluating subtle differences and committing with a higher confidence to a pin either being 'in' or 'out', leading to a potentially higher number of false-positive. The non-radiologists on the other hand may be unsure and be more careful in committing, leading to a lower number of falsepositives but higher false-negatives, therefore increasing the specificity.

CT has the benefit of producing transverse images that can evaluate the vertebral canal in cross section. CT evaluation of the vertebral column also allows for elimination of superimposed structures such as soft tissues, bone and foreign material like PMMA. It gives the evaluator the ability to display images in different gray scales to improve visualization of certain structures and to reformat images in different anatomic planes. ${ }^{39,40}$ Implants can also clearly be identified as being left or right, eliminating one potential for error. One disadvantage of using CT for evaluation of post-surgical spinal stabilization is the artifact created by metallic implants. Metal within the field of view on CT produces artifacts because of a combination of beam hardening and high density edge gradients (undersampling). This causes a combination of bright and dark streaks across the image, which obscures both anatomy and implant margins. ${ }^{41}$ Also, blooming artifact causes metal implants to appear larger than they are in reality. 

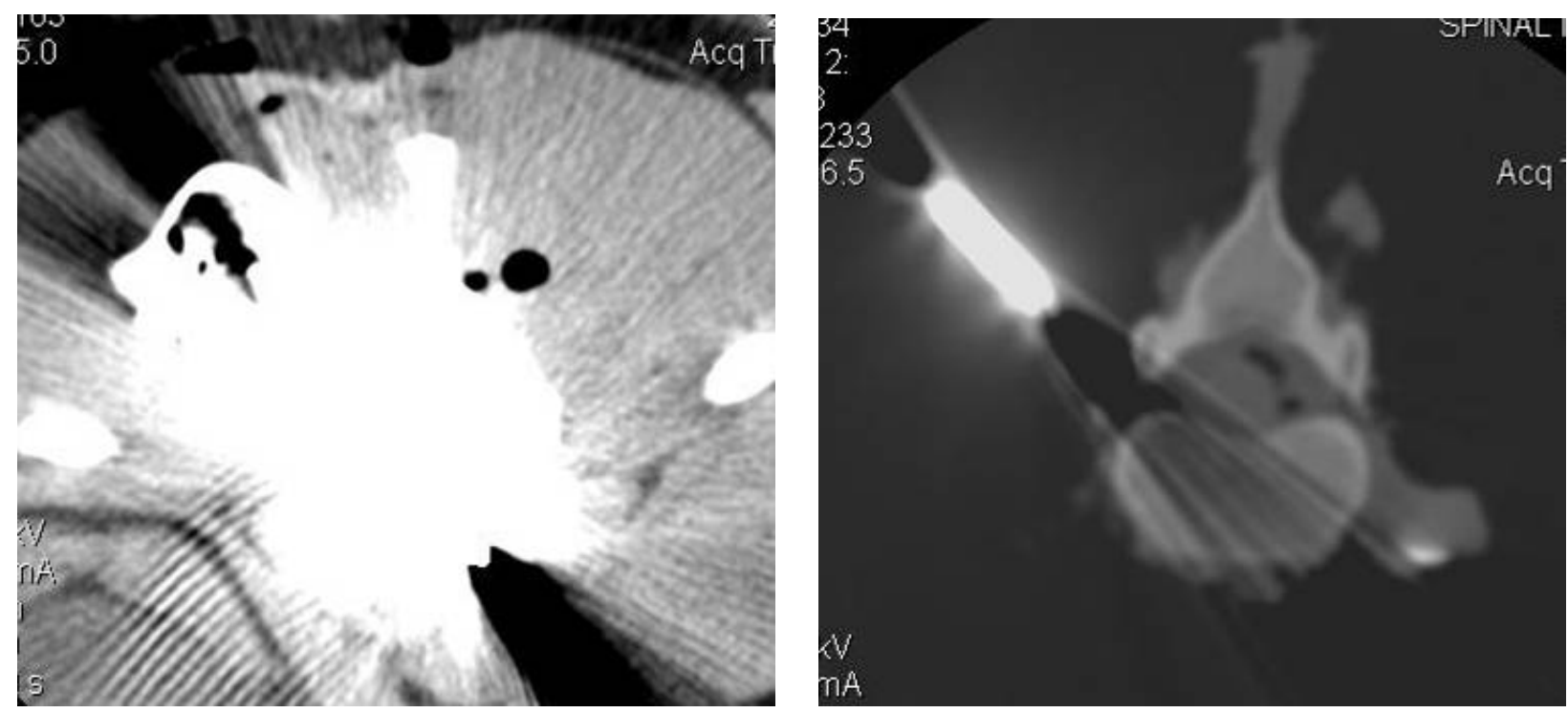

Figure 20: Beam hardening artifact on transverse CT images of the thoracic spine due to presence of a Steinman pin. Left - soft tissue window settings further obliterate vertebral structures and implant margins. Right - despite increasing window level and width, streaking still occurs.

The digital viewing software enabled evaluators to manipulate acquired images and this was beneficial in reducing the bloom artifact by manually increasing the window width and level. This allowed for more defined implant edges and better implant assessment due to greater definition of the different shades of gray. The window width was usually increased to 4000 to 5000 and the window level was increased to 700 to 1300. If bony structures were too indistinct (dark) at these values, the evaluator was able to change the settings as they desired. 

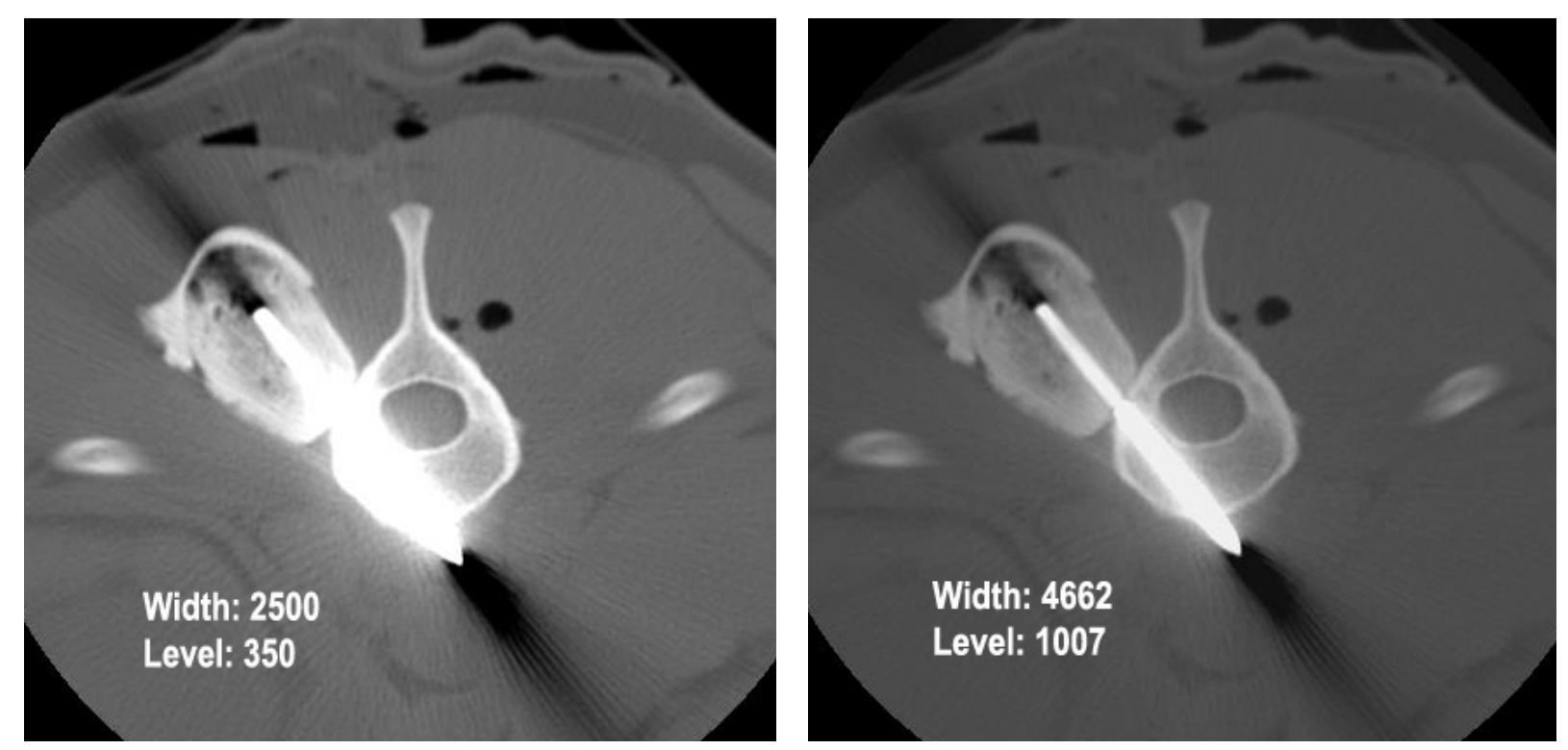

Figure 21: Example of improved implant visibility with higher window width and level. Left - bone window settings improve visibility of vertebral structures and implant but the blooming artifact still makes it difficult to assess pin margins. Right - increased window width and level allow for better implant margin definition.

Before the availability of $\mathrm{CT}$, if the position of an implant was uncertain radiographically, options were usually limited to surgical exploration with implant adjustment or recovery from anesthesia with subsequent neurologic assessment for possible worsening. This could lead to adequately positioned implants being removed or to delayed removal of implants penetrating the vertebral canal and causing neurologic deficits. Whereas this study does not provide a means to improve implant placement at surgery, it does provide a way to assess postoperative implant positioning before anesthetic recovery. With better assessment, mal-positioned implants can be addressed immediately facilitating early resolution of injury and avoidance of subsequent implantrelated clinical signs.

Another limitation of this study is that we cannot correlate the degree of canal violation with clinical signs in dogs. In people, $4-8 \mathrm{~mm}$ of vertebral canal compromise has been reported in 6 clinical cases with development of minor neurologic complications that spontaneously resolved in 2 cases. ${ }^{42}$ No data are available in the 
veterinary literature regarding the effect of implant-related canal violation. Vertebral canal diameters are substantially smaller in most dogs compared with people and extrapolation of findings from human spinal studies has to be done with care. Also, certain breed-specific differences in vertebral canal to spinal cord ratio have been reported. The spinal cord to vertebral canal ratio is higher in Dachshunds when compared with German Shepherd dogs. ${ }^{43}$ Small dogs in general appear to have relatively larger spinal cord diameter compared with larger dogs making the subarachnoid space relatively narrower and forcing the spinal cord to conform closely to the vertebral canal along the entire spine. ${ }^{44,45}$ For these reasons even a slight compromise of the vertebral canal diameter may lead to clinical signs, especially in a small breed dog. It is unknown what degree of implant penetration into the canal will cause neurologic deficits in dogs.

While postoperative radiographs - as determined in this study - are less useful in determining implant position in relation to the vertebral canal, they still hold value for assessment of overall implant location. For follow-up visits, it is more practical to obtain traditional radiographs rather than $C T$, which should be sufficient to evaluate whether implants appear stable or have failed, loosened or migrated. Therefore it is still recommended to obtained standard postoperative radiographic views to allow comparison with future radiographs. 


\section{Conclusion}

We have defined the accuracy of radiography and computed tomography in predicting implant penetration into the vertebral canal for an experimental setting. CT significantly improves an evaluator's ability to identify implant-related canal penetration.

Our study showed that if an implant clearly penetrated the vertebral canal or was clearly contained within the vertebral bone, then evaluators were almost always able to correctly identify its position on CT. Some degree of misinterpretation with CT may be caused by minor implant penetration into the vertebral canal or implant positioning very close to the cortical surface. These implants tended to be misinterpreted as violating the canal, which is likely because of overestimation of pin size from metal bloom artifact. This was also true for radiographs; however, overall accurate identification of implant position was significantly worse. 


\section{Clinical Application}

Case example

A 2-year old female spayed Pit-bull Terrier presented with a T3-L3 myelopathy and paraplegia with intact superficial nociception after being hit by a car. Survey radiographs of the thoracolumbar spine documented subluxation of T12-T13. A preoperative CT was obtained to determine if bony injury or extradural spinal cord compression was present. Computed tomography images were also used for preoperative planning. A dorsal approach to the left side of the thoracolumbar junction was performed. The subluxated vertebrae were reduced and maintained in reduction with a transarticular Kirschner wire across the articular processes. The ends of the $k$ wire were carefully bent dorsally to prevent migration. A total of 6 positive-profile Steinman pins were placed in bicortical fashion on the left side cranially and caudal to the site of subluxation. Polymethylmethacrylate was applied to the Steinman pins and part of the k-wire. Postoperatively, radiographs were obtained to assess reduction of the vertebral subluxation and general implant position (Figure 22). Computed tomography was performed to assure proper pin position within the vertebral pedicle and body (Figure 23). The dog recovered very good motor function postoperatively but remained ataxic in both pelvic limbs (follow-up time - 18 months).

Postoperative CT allowed certain determination that all implants were correctly placed within the vertebrae and none of them violated the vertebral canal or intervertebral foramen. This gave us confidence that any lack of or delay in neurologic improvement was not due to iatrogenic injury from pin placement. Computed tomography also assured us that pins were placed in a substantial amount of bone and that overall implant stability should be excellent. 

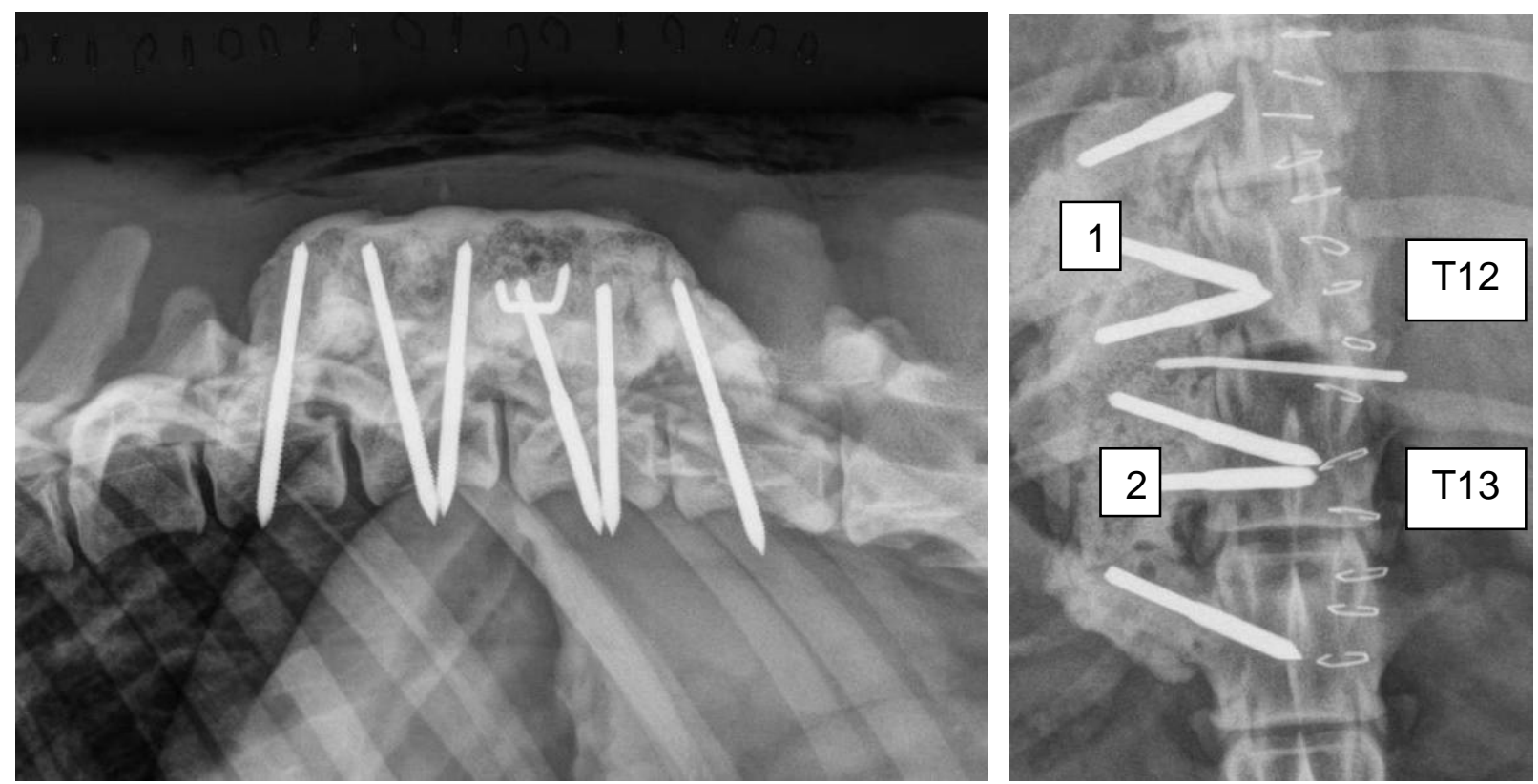

Figure 22: Postoperative lateral (left) and ventrodorsal (right) radiograph of the Pit-bull showing pin/PMMA fixation and a transarticular k-wire.
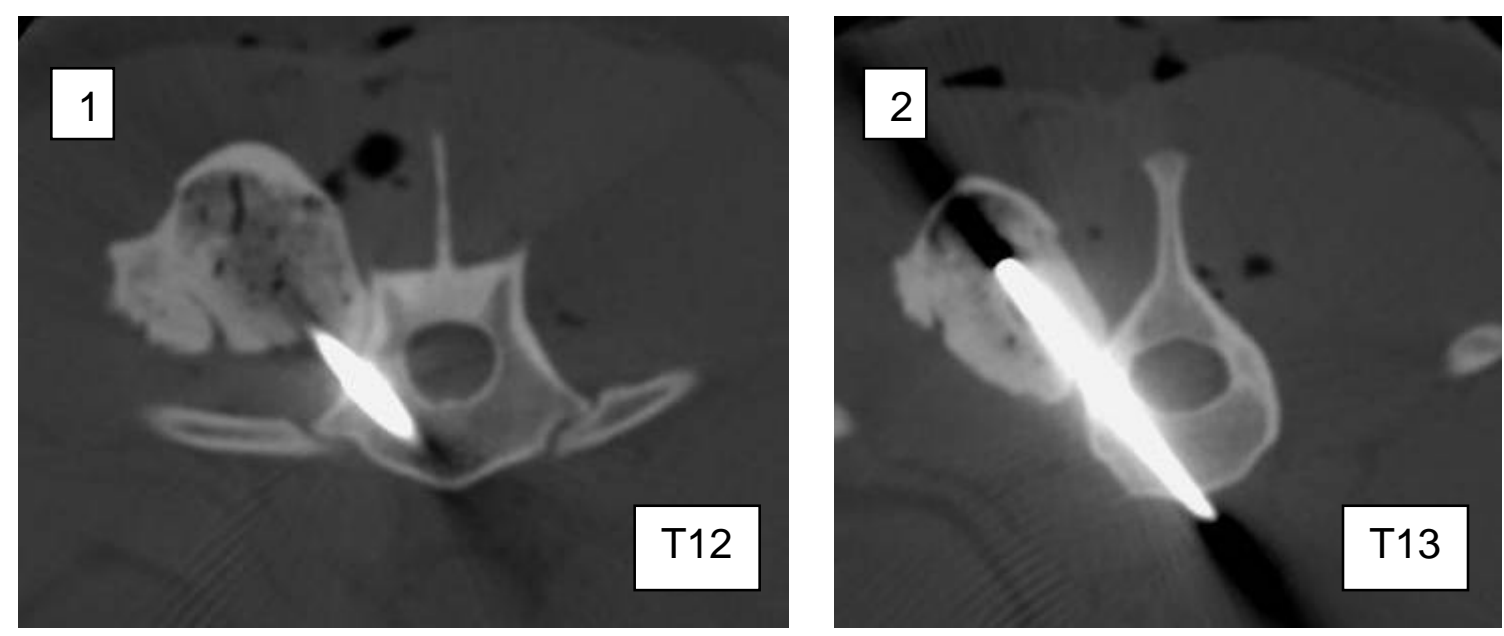

Figure 23: Postoperative CT of the Pit-bull showing pin 1) and pin 2) of previous figure. Note: both pins are within the pedicle and vertebral body and neither pin is violating the vertebral canal. 


\section{Possible Solutions}

While preparing this manuscript and reviewing the literature it became apparent that much theoretical information is available on ideal implant placement into the vertebral column. Unfortunately, values for angles, corridor widths and lengths and even landmarks do not protect from a malpositioned implant. Focus should now be placed on ways to ensure that the recommendations can actually be applied in a clinical setting. If bicortical implant placement remains a higher risk procedure, alternative implant methods should be evaluated. Several areas could be investigated for their use to decrease the potential for iatrogenic spinal cold injury through implants.

\section{Preoperative Imaging}

Preoperative CT would provide precise information of individual vertebrae of the patient. It can display the actual size and any anatomic variations that may be present. It would allow the surgeon to perform measurements from visible landmarks and determine the best insertion angle for a particular point of entry. While it would still not eliminate potential for damage, it should improve accuracy of implant placement.
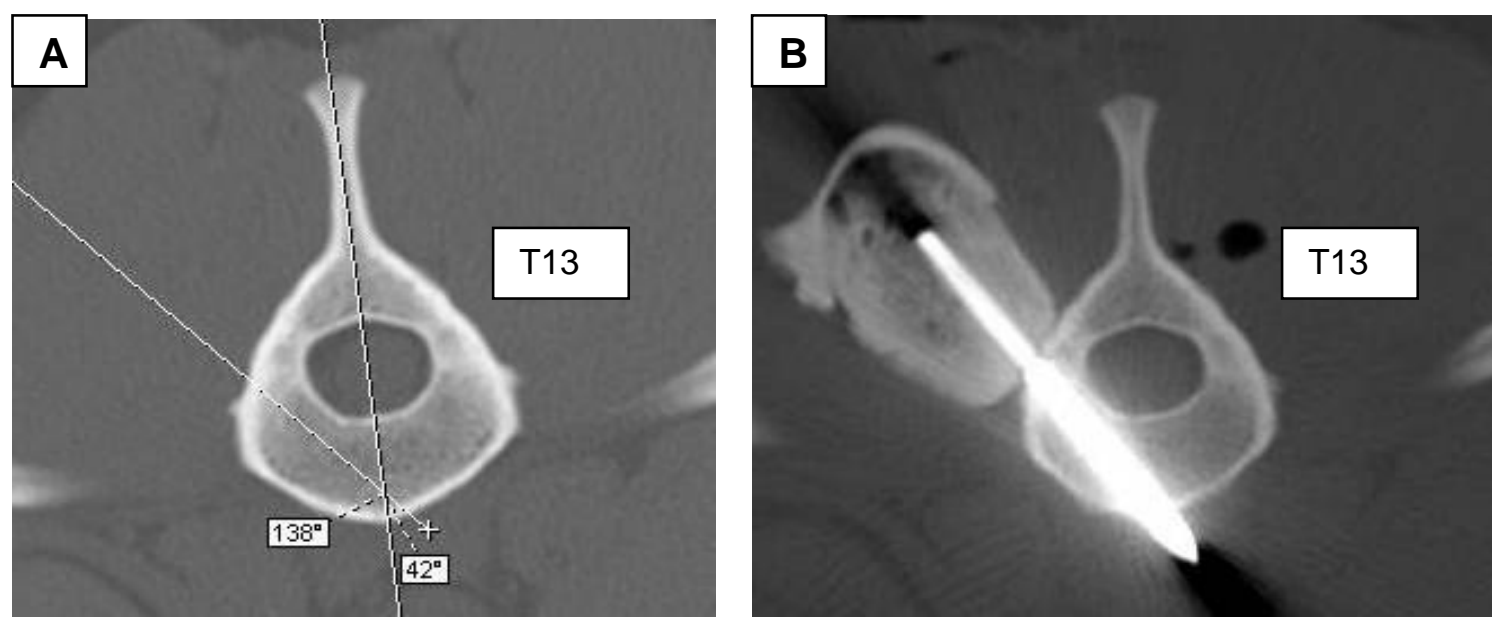

Figure 24: (A) Transverse preoperative CT image through T13 of the two-year old Pitbull with traumatic T12-T13 subluxation. An acceptable insertion angle has been drawn. (B) Postoperative CT of pin/PMMA fixation in the same dog at the same level as (A) 
showing a positive-profile pin without vertebral canal violation and proper bone purchase.

If one has the ability to perform 3-D CT reconstruction it may further aid in identifying individual landmarks and patient specific insertion angles.

Intraoperative Imaging

Intraoperative fluoroscopy appears to improve reliable and safe spinal implant placement and also decreases the risk of injury to vital structures ${ }^{13}$. Another benefit is the potential to perform closed spinal stabilization if external fixation is chosen. Wheeler at al have shown in an in vitro ${ }^{13}$ and in vivo ${ }^{46}$ clinical study that fluoroscopically placed external fixator pins are save and have a decreased risk of iatrogenic injury to the spinal cord and vasculature but clinical patient numbers are small. A larger number of clinical cases should be assessed to further evaluate the benefits of intraoperative fluoroscopy.

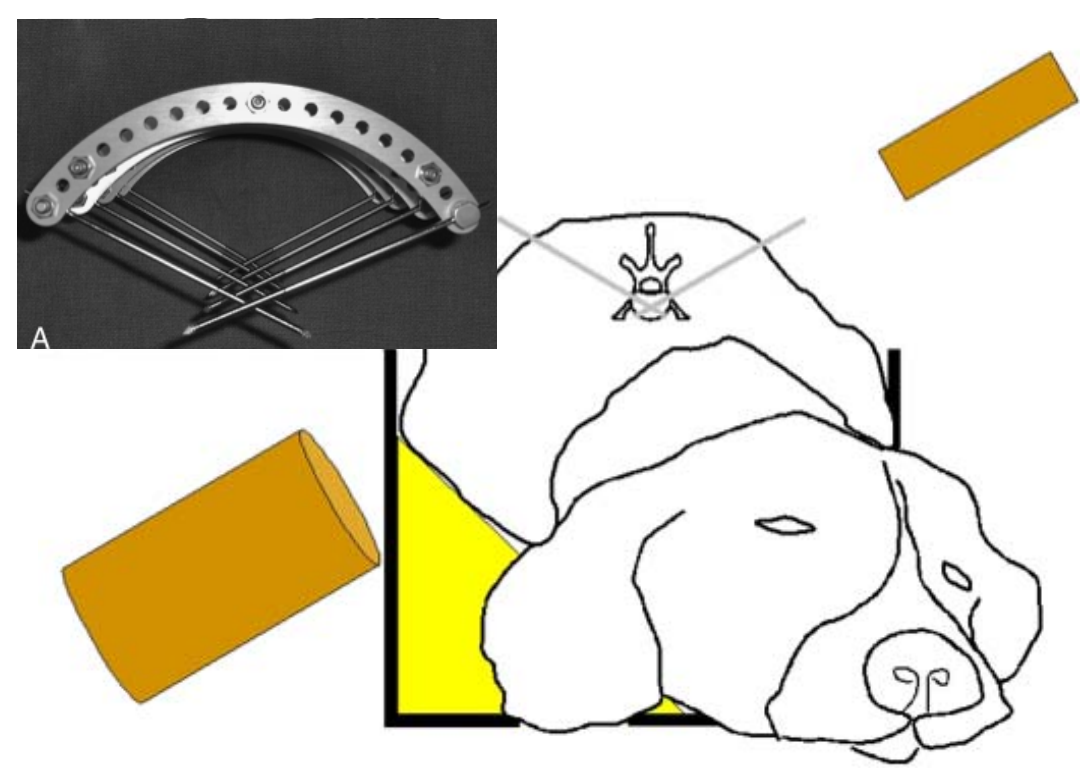

Figure 25: Closed application of an external fixator spinal arch using fluoroscopy. Modified from Wheeler et al ${ }^{46}$, Vet Surg 2007.

Spinal implant placement may be facilitated by the use of intraoperative CT, which would also allow placement of pins in a minimally invasive fashion (i.e. via 
external fixation). General concerns may be radiation exposure to the patient and surgical team as well as challenges with implant placement in the confinement of the CT unit.

Computer assisted surgical navigation positioning systems may allow surgeons to adhere to safe implant corridors as well as applying implants in a minimally invasive approach. These systems are currently used for human joint replacement surgeries but have great potential for a variety of procedures including vertebral column stabilization. Cost will likely be a limiting factor for the application of these devices in veterinary medicine.

Modification of Spinal Implants

If despite best efforts there remains a risk of neurovascular injury with bicortical implants, efforts should be directed toward the evaluation of different fixation systems. Particularly for the cervical spine, use of monocortical implants should be considered to prevent vertebral canal violation or injury to structures within the transverse and intervertebral foramen. Clinically, placement of monocortical screws either with PMMA or locking plates has been performed without major complications; however, biomechanical data evaluating the performance of monocortical to bicortical implants is still lacking.

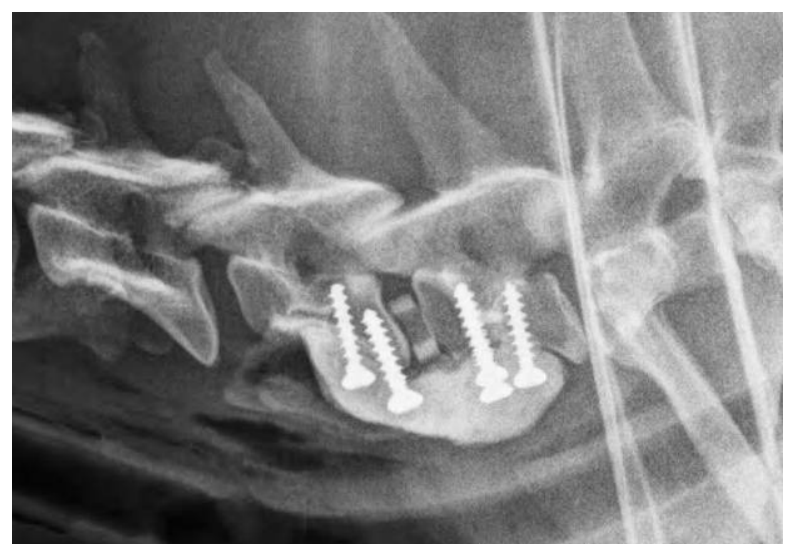

Figure 26: Monocortical screw and PMMA stabilization of C6 and C7 in a Rottweiler suffering from caudal cervical spondylomyelopathy. 


\section{Summary}

Vertebral column stabilization is performed for dogs suffering from instability secondary to trauma, neoplasia, caudal cervical spondylomyelopathy, infection and other. A common stabilizing technique involves bicortical placement of positive profile endthreaded Steinman pins into the vertebral body and pedicles. Bicortical placement of these pins carries a high risk for iatrogenic trauma of important neurovascular structures. A clinical frustration has been the difficulty determining exact implant position based on postoperative conventional spinal survey radiographs. Implant position within the vertebral column may be better determined using a different imaging modality such as computed tomography as this would allow for evaluation of tissues in different anatomic planes.

The goal of this study was to compare the accuracy of radiography and computed tomography in predicting implant position in relation to the vertebral canal in the cervical and thoracolumbar vertebral column in an in vitro imaging and anatomic study. Twelve medium-sized canine cadaver vertebral columns were utilized for this study.

Steinman pins were placed into cervical and thoracolumbar vertebrae based on established landmarks but without predetermination of vertebral canal violation. Radiographs and CT exams were obtained and evaluated by 6 individuals. A random subset of pins was evaluated for ability to distinguish left from right pins on radiographs. The ability of the examiner to correctly identify vertebral canal penetration for all pins was assessed both on radiographs and $\mathrm{CT}$. Spines were then anatomically prepared and visual examination of pin penetration into the canal served as the gold standard.

Results revealed a left/right accuracy of $93.1 \%$. Overall sensitivity of radiographs and CT to detect vertebral canal penetration by an implant were significantly different and estimated as $50.7 \%$ and $93.4 \%$, respectively $(P<0.0001)$. Sensitivity was significantly higher for complete vs. partial penetration and for radiologists vs. non-radiologists for both imaging modalities. Overall specificity of radiographs and CT to detect vertebral canal penetration was $82.9 \%$ and $86.4 \%$, respectively $(P=0.049)$.

In conclusion, CT was superior to radiographic assessment and is the recommended imaging modality to assess penetration into the vertebral canal. The clinical relevance of 
this finding is that $\mathrm{CT}$ is significantly more accurate in identifying vertebral canal violation by Steinman pins and should be performed postoperatively to assess implant position. 


\section{Zusammenfassung}

\section{Titel: Genauigkeit konventioneller Röntgenaufnahmen und Computer Tomographie in der Bewertung von Implantatpositionen in Relation zum Wirbelkanal in Hunden}

Die Wirbelsäulenstabilisation ist für Hunde indiziert, die an einer Instabilität nach Trauma, Neoplasie, kaudaler Zervikospondylomyelopathie, Infektion oder anderem leiden. Eine häufig angewandte Stabilisierungstechnik ist das bikortikale Setzen von profilierten Steinmann Gewindenägeln in den Pediculus und Corpus vertebrae. Bikortikale Implantate bergen ein erhöhtes iatrogenes Verletzungsrisiko für wichtige neurovaskuläre Strukturen. In der klinischen Arbeit ist die Schwierigkeit frustrierend, anhand von postoperativen Röngtenaufnahmen die genaue Lage von Implantaten festzustellen. Die Implantatposition innerhalb der Wirbelsäule kann gegebenenfalls besser mit anderen bildgebenden Verfahren wie der Computertomographie festgestellt werden, da diese anatomische Strukturen in unterschiedlichen Ebenen darstellen kann.

Das Ziel dieser Studie war, die Eignung von Röntgenaufnahmen und Computertomographie bezüglich der genauen Lagebestimmung eines Implantats im Verhältnis zum Wirbelkanal zu vergleichen. Dies wurde in einer anatomischen in-vitroStudie an kaninen zervikalen und thorakolumbalen Wirbelsäulen mit den beiden genannten bildgebenden Verfahren getestet. Dazu wurden die Wirbelsäulen von zwölf mittelgroßen Hunden verwendet.

Steinmann Nägel wurden nach veröffentlichten Empfehlungen und erkennbaren Markierungen in zervikale und thorakolumbale Wirbel gesetzt. Dabei wurden keine Vorgaben zur Verletzung des Wirbelkanals gemacht.

Röntgen- und CT-Aufnahmen wurden von sechs verschiedenen Personen beurteilt. Zuerst wurde an einem Teil zufällig gesetzter Nägel die Fähigkeit geprüft, rechte von linken Implantaten unterscheiden zu können. Dann wurde an allen Implantaten die Fähigkeit des Untersuchers getestet, die Verletzung des Wirbelkanals durch einen Nagel auf Röntgenaufnahmen oder CT korrekt einzuschätzen. Wirbelsäulen wurden 
danach anatomisch präpariert und die visuelle Untersuchung einer möglichen Verletzung des Wirbelkanals durch einen Pin diente als Goldstandard.

Die statistische Analyse zeigt eine Genauigkeit der Links/Rechts-Bestimmung von 93.1\%. Die Sensitivität, eine Wirkelkanalverletzung durch ein Implantat mit Röntgenaufnahmen und CT zu entdecken war 50.7\% (Röntgen) and 93.4\% (CT); dieser Unterschied war signifikant $(P<0.0001)$. Die Sensitivität für eine vollständige Penetration des Wirbelkanals war signifikant höher als für eine teilweise Verletzung. Ebenso war bei beiden bildgebenden Verfahren die Sensitivität höher für Radiologen im Vergleich zu nicht-Radiologen. Die Spezifität, eine Wirbelkanalpenetration mit Röntgenaufnahmen und CT zu entdecken, lag bei 82.9\% (Röntgen) und 86.4\% (CT, p = 0.049).

Zusammenfassend lässt sich sagen, dass die CT der röntgenologischen Bewertung weit überlegen und das empfohlene bildgebende Verfahren zur Diagnose von Verletzungen des Wirbelkanals ist. Die klinische Bedeutung dieses Ergebnisses liegt in der signifikant genaueren Identifikation von kanal-verletzenden Implantaten durch die Computertomographie. Deshalb sollte eine CT-Untersuchung postoperativ durchgeführt werden, um die Lage der Wirbelsäulenimplantate zu bewerten. 


\section{References}

1. Palmer $\mathrm{RH}$, Chambers JN: Canine lumbosacral disease Part II: Definition, diagnosis, treatment, and prognosis. Comp Cont Ed 13:213-221, 1991.

2. Aikawa $T$, Kanazono $S$, Yoshigae $\mathrm{Y}$, et al: Vertebral stabilization using positively threaded profile pins and polymethylmethacrylate, with or without laminectomy, for spinal canal stenosis and vertebral instability caused by congenital thoracic vertebral anomalies. Vet Surg 36:432-441, 2007.

3. Auger J, Dupuis J, Quesnel A, et al: Surgical treatment of lumbosacral instability caused by discospondylitis in four dogs. Vet Surg 29:70-80, 2000.

4. Dernell WS, Van Vechten BJ, Straw RC, et al: Outcome following treatment of vertebral tumors in 20 dogs (1986-1995). J Am Anim Hosp Assoc 36:245-251, 2000.

5. Swaim SF: Evaluation of four techniques of cervical spinal fixation in dogs. J Am Vet Med Assoc 166:1080-1086, 1975.

6. Blass CE, Waldron DR, Van Ee RT: Cervical stabilization in three dogs using steinmann pins and methyl methacrylate. J Am Anim Hosp Assoc 24:61-68, 1988.

7. Ellison GW, Seim HB, 3rd, Clemmons RM: Distracted cervical spinal fusion for management of caudal cervical spondylomyelopathy in large-breed dogs. J Am Vet Med Assoc 193:447-453, 1988.

8. Voss K, Steffen F, Montavon PM: Use of the ComPact UniLock System for ventral stabilization procedures of the cervical spine: a retrospective study. Vet Comp Orthop Traumatol 19:21-28, 2006.

9. Bergman $\mathrm{RL}$, Levine $\mathrm{JM}$, Coates $\mathrm{JR}$, et al: Cervical spinal locking plate in combination with cortical ring allograft for a one level fusion in dogs with cervical spondylotic myelopathy. Vet Surg 37:530-536, 2008.

10. McKee WM, Downes CJ: Vertebral stabilisation and selective decompression for the management of triple thoracolumbar disc protrusions. J Small Anim Pract 49:536-539, 2008.

11. Zahn K, Matis U: The clamp rod internal fixator - application and results in 120 small animal fracture patients.. Vet Comp Orthop Traumatol 17:110-120, 2004.

12. Walker TM, Pierce WA, Welch RD: External fixation of the lumbar spine in a canine model. Vet Surg 31:181-188, 2002.

13. Wheeler JL, Cross AR, Rapoff AJ: A comparison of the accuracy and safety of vertebral body pin placement using a fluoroscopically guided versus an open surgical approach: an in vitro study. Vet Surg 31:468-474, 2002.

14. Watine S, Cabassu JP, Catheland S, et al: Computed tomography study of implantation corridors in canine vertebrae. J Small Anim Pract 47:651-657, 2006.

15. Blass CE, Seim HB, III: Spinal fixation in dogs using steinmann pins and methylmethacrylate. Vet Surg 13:203-210, 1984.

16. Garcia JN, Milthorpe BK, Russell D, et al: Biomechanical study of canine spinal fracture fixation using pins or bone screws with polymethylmethacrylate. Vet Surg 23:322-329, 1994. 
17. Lanz OI, Jones JC, Bergman R: Use of an external skeletal fixator to correct for spinal fracture/luxation and instability in three dogs.. Vet Neurol Neurosurg J 2, 2000.

18. Corlazzoli D: Bicortical implant insertion in caudal cervical spondylomyelopathy: a computed tomography simulation in affected Doberman Pinschers. Vet Surg 37:178-185, 2008.

19. Bali MS, Lang J, Jaggy A, et al: Comparative study of vertebral fractures and luxations in dogs and cats. Vet Comp Orthop Traumatol 22:47-53, 2009.

20. Feeney DA, Oliver JE: Blunt spinal trauma in the dog and cat: insight into radiographic lesions.. Journal of the American Animal Hospital Association 16:885-890, 1980.

21. Shores A: Spinal trauma: pathophysiology and management of traumatic spinal injuries.. Veterinary Clinics of North America Small Animal Practice 22:859-888, 1992.

22. Shores A, Braund KG, Brawner WR: Management of acute spinal cord trauma. Journal of Veterinary Medicine 85:724-739, 1990.

23. Curry TS, Dowdey JE, Murray RC: Computed Tomography, in Christensen's Physics of Diagnostic Radiology (ed 4th), Vol Philadelphia, Lippincott Williams \& Wilkins, 1990, pp 289-322.

24. Learch TJ, Massie JB, Pathria MN, et al: Assessment of pedicle screw placement utilizing conventional radiography and computed tomography: a proposed systematic approach to improve accuracy of interpretation. Spine 29:767-773, 2004.

25. Kim HS, Heller JG, Hudgins PA, et al: The accuracy of computed tomography in assessing cervical pedicle screw placement. Spine 28:2441-2446, 2003.

26. Farber GL, Place HM, Mazur RA, et al: Accuracy of pedicle screw placement in lumbar fusions by plain radiographs and computed tomography. Spine 20:14941499, 1995.

27. Yoo JU, Ghanayem A, Petersilge C, et al: Accuracy of using computed tomography to identify pedicle screw placement in cadaveric human lumbar spine. Spine 22:2668-2671, 1997.

28. Choma TJ, Denis F, Lonstein JE, et al: Stepwise methodology for plain radiographic assessment of pedicle screw placement: a comparison with computed tomography. J Spinal Disord Tech 19:547-553, 2006.

29. Kinns J, Mai W, Seiler G, et al: Radiographic sensitivity and negative predictive value for acute canine spinal trauma. Vet Radiol Ultrasound 47:563-570, 2006.

30. Feeney DA, Oliver JE: Blunt spinal trauma in the dog and cat insight into radiographic lesions. J Am Anim Hosp Assoc 16:885-890, 1980.

31. Campbell MK, Mollison J, Grimshaw JM: Cluster trials in implementation research: estimation of intracluster correlation coefficients and sample size. Stat Med 20:391-399, 2001.

32. Ukoumunne OC: A comparison of confidence interval methods for the intraclass correlation coefficient in cluster randomized trials. Stat Med 21:3757-3774, 2002.

33. Killip S, Mahfoud Z, Pearce K: What is an intracluster correlation coefficient? Crucial concepts for primary care researchers.. Ann Fam Med 2:204-208, 2005. 
34. Scheaffer RL, Mendenhall W, Ott RL: Elementary survey sampling (ed 5th), Belmont: Wadsworth Publishing Company, 1996.

35. Fleiss JL, Levin BA, Paik MC: Statistical methods for rates and proportions (ed 3rd), Wiley-Interscience, 2003.

36. Koehler CL, Stover SM, LeCouteur RA, et al: Effect of a ventral slot procedure and of smooth or positive-profile threaded pins with polymethylmethacrylate fixation on intervertebral biomechanics at treated and adjacent canine cervical vertebral motion units. Am J Vet Res 66:678-687, 2005.

37. Anderson MA, Mann FA, Wagner-Mann C, et al: A comparison of nonthreaded, enhanced threaded, and Ellis fixation pins used in type I external skeletal fixators in dogs. Vet Surg 22:482-489, 1993.

38. Greenland S: Multiple comparisons and association selection in general epidemiology. Int J Epidemiol 37:430-434, 2008.

39. Sande RD: Radiography, myelography, computed tomography, and magnetic resonance imaging of the spine. Vet Clin North Am Small Anim Pract 22:811831, 1992.

40. Wortman JA: Principles of X-ray computed tomography and magnetic resonance imaging. Semin Vet Med Surg (Small Anim) 1:176-184, 1986.

41. Rinkel J, Dillon WP, Funk T, et al: Computed tomographic metal artifact reduction for the detection and quantitation of small features near large metallic implants: a comparison of published methods. J Comput Assist Tomogr 32:621-629, 2008.

42. Gertzbein SD, Robbins SE: Accuracy of pedicular screw placement in vivo. Spine 15:11-14, 1990.

43. Morgan JP, Atilola M, Bailey CS: Vertebral canal and spinal cord mensuration: a comparative study of its effect on lumbosacral myelography in the dachshund and German shepherd dog. J Am Vet Med Assoc 191:951-957, 1987.

44. Fourie SL, Kirberger RM: Relationship of cervical spinal cord diameter to vertebral dimensions: A radiographic study of normal dogs. Vet Radiol Ultrasound 40:137143, 1999.

45. Lamb CR: Common difficulties with myelographic diagnosis of acute intervertebral disc prolapse in the dog. J Small Anim Pract 35:549-558, 1994.

46. Wheeler JL, Lewis DD, Cross AR, et al: Closed fluoroscopic-assisted spinal arch external skeletal fixation for the stabilization of vertebral column injuries in five dogs. Vet Surg 36:442-448, 2007. 


\section{List of figures}

Figure 1: Craniolateral view of the 5th (left) and caudal view of the 7th cervical vertebra. From: Miller's Anatomy of the dog, 3rd edition, WB Saunders 1993.

Figure 2: Lateral view of the 1st (left) and craniolateral view of the 6th thoracic vertebra. From: Miller's Anatomy of the dog, 3rd edition, WB Saunders 1993.

Figure 3: Craniolateral view of the 1st (left) and caudolateral view of the 5th lumbar vertebra. From: Miller's Anatomy of the dog, 3rd edition, WB Saunders 1993.

Figure 4: Schematic drawing of sagittally sectioned lumbar vertebrae of a dog. Modified from König, Liebich. Anatomy of domestic mammals. 3rd edition. Schattauer, 2006.

Figure 5: Specimens of vertebra C6 (left), T12 (center) and L3 (right) of a medium sized dog $(25 \mathrm{~kg})$ showing anatomic differences between vertebrae of different locations within the

Figure 6: Canine specimens of vertebra C6 (left), T12 (center) and L3 (right) showing traditional bicortical placement of pins through vertebral body and pedicle.

Figure 7: Example of a pin/PMMA construct in the cervical vertebral column. Illustration from Fossum's Textbook of Small Animal Surgery, 2nd edition, 2002, Mosby.

Figure 8: Example of a pin/PMMA construct in the TL vertebral column. A: fixation of an intervertebral articulation. B: fixation of an unstable vertebra.

Figure 9: Left - lubra plate applied to the lumbar spine; right - spinal stapling used at the thoracolumbar junction. 
Figure 10: Transverse computed tomography section C6 (A), T11 (B) and L1 (C) showing recommended widths and lengths of implant insertion corridors and angle between insertion corridor and sagittal plane. Proximity to important vascular structures is evident ( $A$ : vertebral artery and vein in transverse foramen; $B: 1$ Aorta, 2 Azygos vein; C: 1 Aorta, 2 Caudal vena cava). Modified from Watine14, JSAP 2006.

Figure 11: Intraoperative view of a thoracolumbar spinal fixation using pins and subsequently applied PMMA. Note the degree of soft tissue disruption but the remaining limited exposure of the vertebral column in this area.

Figure 12: Ventral aspect of a canine cadaveric cervical spine with pins placed in vertebral bodies C2-C7.

Figure 13: Canine cadaveric thoracolumbar spine with pins placed in vertebral bodies bilaterally from dorsolateral to ventromedial.

Figure 14: Two PMMA bars applied dorsolaterally to a cadaveric thoracolumbar spine.

Figure 15: One PMMA bar applied ventrally to a cadaveric cervical spine.

Figure 16: A) Lateral radiograph of a cervical and B) dorsoventral radiograph of a thoracolumbar vertebral column. PMMA bars are applied to the thoracolumbar spine and individual pins are labeled.

Figure 17: A) Axial CT images of $\mathrm{C} 4$ with pin in foramen but not compromising vertebral canal (white arrow); B) T12 vertebra with 1 pin partially penetrating vertebral canal (black arrow) and 1 pin not penetrating the cortex (black arrow head); L4 vertebra with pin completely penetrating vertebral canal (black arrow).

Figure 18: A) Caudal view of C4 vertebra with pin in foramen but not compromising vertebral canal (black arrow - same as Fig 2A); B) caudal view of T12 vertebra with 1 
pin partially penetrating canal (black arrow - same as Fig 2B) and normal inner vertebral cortex (arrow head); C) caudal view of L4 vertebra with pin completely penetrating canal (black arrow - same as Fig 2C).

Figure 19: Section of a VD projection of the cervical spine (left) and of a DV projection of the lumbar spine documenting the difficulty to determine left and right pins with certainty, especially in the cervical spine.

Figure 20: Beam hardening artifact on transverse CT images of the thoracic spine due to presence of a Steinman pin. Left - soft tissue window settings further obliterate vertebral structures and implant margins. Right - despite increasing window level and width, streaking still occurs.

Figure 21: Example of improved implant visibility with higher window width and level. Left - bone window settings improve visibility of vertebral structures and implant but the blooming artifact still makes it difficult to assess pin margins. Right - increased window width and level allow for better implant margin definition.

Figure 22: Postoperative lateral (left) and ventrodorsal (right) radiograph of the Pit-bull showing pin/PMMA fixation and a transarticular k-wire.

Figure 23: Postoperative CT of the Pit-bull showing pin 1) and pin 2) of previous figure. Note: both pins are within the pedicle and vertebral body and neither pin is violating the vertebral canal.

Figure 24: (A) Transverse preoperative CT image through T13 of the two-year old Pitbull with traumatic T12-T13 subluxation. An acceptable insertion angle has been drawn. (B) Postoperative CT of pin/PMMA fixation in the same dog at the same level as (A) showing a positive-profile pin without vertebral canal violation and proper bone purchase. 
Figure 25: Closed application of an external fixator spinal arch using fluoroscopy. Modified from Wheeler et al46, Vet Surg 2007.

Figure 26: Monocortical screw and PMMA stabilization of $\mathrm{C} 6$ and $\mathrm{C} 7$ in a Rottweiler suffering from caudal cervical spondylomyelopathy. 


\section{List of tables}

Table 1: Recommended insertion angles14 and landmarks for bicortical spinal implants.

Table 2: Sensitivity of radiographic and computed tomography (CT) assessment of implant position within vertebral column.

Table 3: Specificity of radiographic and computed tomography (CT) assessment of implant position within vertebral column.

Table 4: Left - right determination for radiography and sensitivity and specificity of radiographic and computed tomography (CT) assessment of implant position within vertebral column compared to assessor's level of confidence. 


\section{Acknowledgement}

I would like to acknowledge my co-authors Geoff Fosgate, Sharon Kerwin, Jon Levine, Ben Young, Mike Walker and Jay Griffin for their valuable time and effort during the evaluation of hundreds of vertebral pins. Thank you for refraining from stabbing me with one of them!

My appreciation also goes to PD Dr. Johann Maierl who has greatly facilitated the process of writing and submitting this dissertation. From the first time we dissected a wallaby until now, you have been a wonderful mentor and friend.

To my dear friends Sharon Kerwin \& the boys and Kathleen \& Alan Wolfenden - thank you for having been family away from home during my years in Texas.

Most importantly I want to wholeheartedly thank my mother Dorise, my sisters Claudia and Malaika as well as my brother-in-law Robin for their love, encouragement, advice and support. You helped me persevere and succeed. And as my Oma has told me many times: Rome was also not built in one day. I am fortunate to have such a special family!

Lastly, I would like to let my father know how grateful I am for the values and ideals he passed on to me. If only you could be here. 